\title{
The effectiveness of the counter-cyclical loan-to-value regulation: Generic versus sector-specific rules
}

\author{
GUANGLING LIU
}

THABANG MOLISE

Stellenbosch Economic Working Papers: WP21/2019

www.ekon.sun.ac.za/wpapers/2019/wp212019

December 2019

KEYWORDS: Macro-prudential policy, Counter-cyclical LTV regulation, DSGE, Financial stability, Household credit, Corporate credit JEL: E32, E37, E44, E51, G28 


\title{
The effectiveness of the counter-cyclical loan-to-value regulation: Generic versus sector-specific rules
}

\author{
Guangling Liu* and Thabang Molise ${ }^{\dagger}$
}

August 14, 2019

\begin{abstract}
This paper considers the implications of the counter-cyclical loan-to-value (CcLTV) regulation in a setting where different types of borrowers from distinct sectors of the credit market co-exist. To identify the optimal policy design, we consider two macro-prudential policy regimes, nanely generic and sector-specific, and compare their effectiveness in enhancing financial and macroeconomic stability. The results show that both regimes are effective in this regard, especially when the economy is hit by financial and housing demand shocks. The effectiveness of both regimes is, however, shock-dependent. To enhance the effectiveness of CcLTV regulation, we argue that the regulator should consider borrowers' heterogeneity and the origin of the shocks, and tailor the CcLTV regulation according to the specific conditions of each sector of the credit market, rather than to the aggregate conditions. In this way, the regulator can directly target the specific sector or borrower type.
\end{abstract}

Keywords: Macro-prudential policy, Counter-cyclical LTV regulation, DSGE, Financial stability, Household credit, Corporate credit.

JEL Classification: E32, E37, E44, E51, G28

\footnotetext{
*Corresponding author: Department of Economics, University of Stellenbosch, and South African Reserve Bank. E-mail address: gliu@sun.ac.za

$\dagger$ Department of Economics, University of Stellenbosch, Stellenbosch, 7602, South Africa. Email address: molise42@gmail.com
} 


\section{Introduction}

Policy makers and academics have been emphasising the role of macro-prudential policy in strengthening the resilience of the financial system and fostering financial stability since the 2007/08 global financial crisis. One of the key issues is the design of the macro-prudential policy. This includes measures to reduce the systemic risk that arises from excessive fluctuations in credit supply and the pro-cyclical nature of the financial sector (Claessens et al.; 2013). One of these measures is the counter-cyclical loan-to-value (CcLTV) ratio. The intuition behind the CcLTV regulation is to adjust the LTV ratio in a countercyclical manner to lean against the credit cycle. During an economic boom, the LTV ratio is tightened in order to dampen the excessive credit growth and prevent bubbles, such as a house price bubble. In this way, the regulation can contain the build-up of systemic risk and promote financial stability. When systemic risk materialises, the LTV ratio is relaxed to prevent a sharp decline in the demand for credit, house price collapse and rapid deleverage in the banking sector. This relaxation mitigates the spillover of financial vulnerabilities to the real sector.

While there is consensus that financial regulation is moving towards the macro-prudential approach with well-defined policy toolkits, the design and the implementation of the policy tools remain a challenge. Most studies in the literature examine a unique CcLTV regulation in a model economy regardless of the type of borrower - either household or non-financial corporate or both. ${ }^{1}$ Very few studies examine a borrower-specific CcLTV regulation in a model where borrowers of more than one type from distinct sectors of the credit market co-exist. An exception is the paper by Punzi and Rabitsch (2018), which examines a general equilibrium model with low- and high-leveraged household borrowers and considers the effectiveness of CcLTV regulations that target the two types of household borrowers. This study, however, lacks a rigorous analysis of the CcLTV regulation. It is thus not informative for policymakers looking for the optimal design for the CcLTV regulation in an environment where there are several types of borrowers from distinct sectors of the credit market.

As cyclical patterns of household credit and non-financial corporate credit differ, macro-prudential tools should be designed and implemented to suit the different patterns. Fig. 1 shows how household and corporate credit behaved differently over the sample period 1994Q1 to 2016Q4 in South Africa. Household credit experienced a sustained growth from 2002 to 2008, associated with the South Africa's housing market boom. Before this steep climb, household credit had been decreasing since 1998, and it decreased again after the financial crisis. In contrast, corporate credit had been flat since 1998 and only started catching up with household credit from 2005. It is also worth noting that corporate credit started recovering again from 2013, whereas household credit continued to decline after the crisis. The

\footnotetext{
${ }^{1}$ A non-exhaustive list includes Lambertini et al. (2013), Angelini et al. (2014), Quint and Rabanal (2014), Rubio and Carrasco-Gallego (2014), Mendicino and Punzi (2014), Brzoza-Brzezina et al. (2015), Ravn (2016), Rubio and Yao (2017) and Garbers and Liu (2018). These studies find that the CcLTV regulation delivers more stable financial and macroeconomic conditions and improves social welfare. For example, Lambertini et al. (2013) establish that the CcLTV rule reacting to credit growth is effective in stabilising fluctuations in house prices and credit, and leads to Pareto optimality. Rubio and Carrasco-Gallego (2014) show that the CcLTV rule that responds to changes in credit is effective in mitigating the fluctuations in credit growth and enhances welfare.
} 
figure also shows that the credit-to-output ratio for corporate credit is, on average, above $30 \%$ over the sample period, which is approximately $10 \%$ higher than that of household credit.

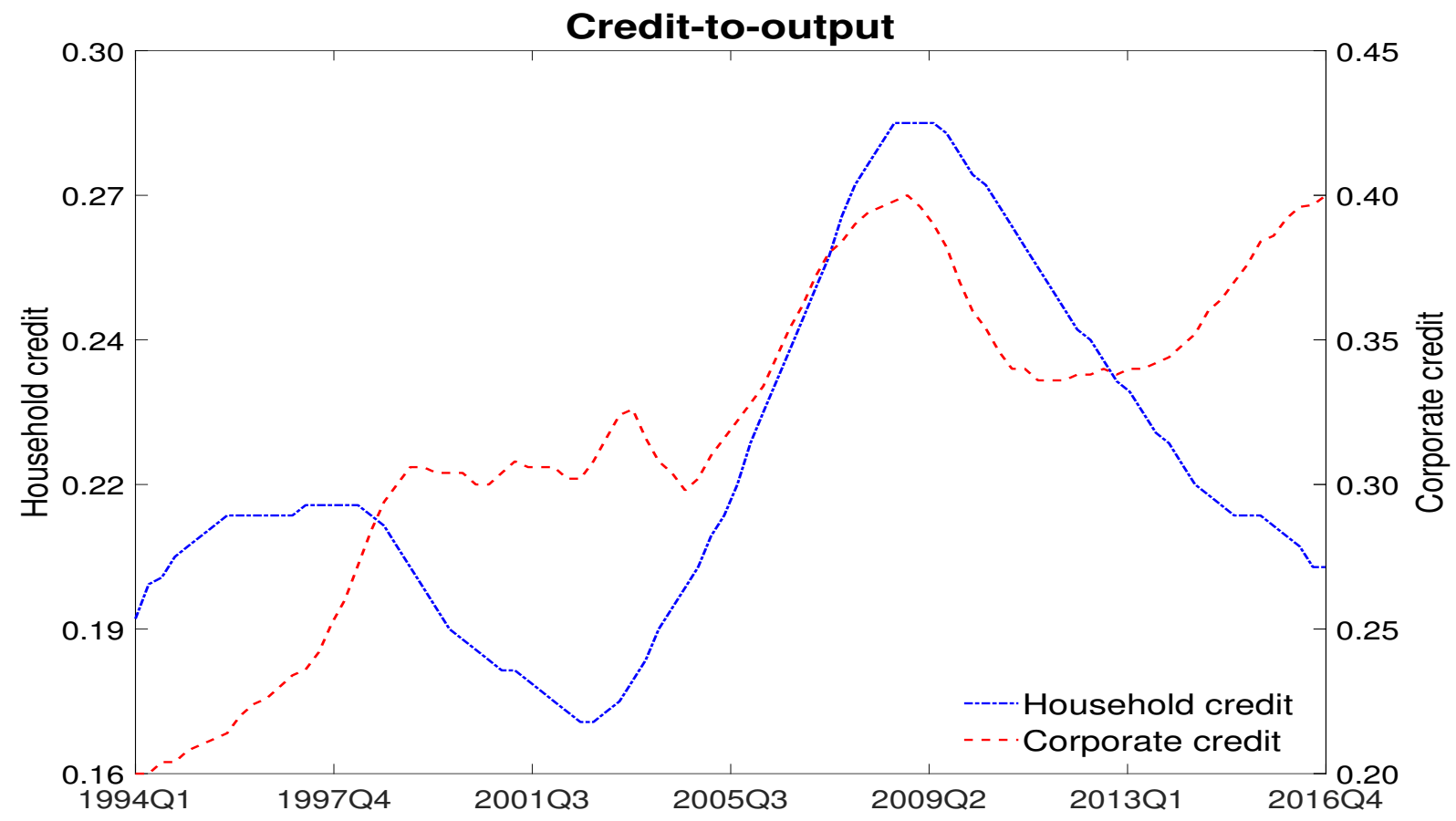

Figure 1: Credit-to-output ratios in South Africa. Data source: South African Reserve Bank.

This paper contributes to the literature on macro-prudential policy by investigating the implications of the CcLTV regulation where heterogeneous borrowers from distinct sectors of the credit market co-exist. Our aim is to identify the optimal design. This is in contrast to studies that consider a single CcLTV regulation in a setting where there is only one type of borrower, or where there are homogeneous borrowers from one sector of the credit market. We argue that fluctuations in different types of credit affect the real economy through different channels. For example, changes in household credit affect the economy through the demand for consumption goods and services and for housing investment, whereas changes in corporate credit affect the economy through investment in physical capital and housing (commercial real estate) and through the demand for labour. That is, changes in household credit affect the economy mainly from the demand side, whereas changes in corporate credit affect the economy mainly from the supply side. The regulatory authority should therefore assess potential risks in specific sectors of the credit market and implement the CcLTV accordingly. This would avoid the potential costs that arise from implementing a one-size-fits-all CcLTV, which over-reacts in a sector of the market where there are no risks and under-reacts in one where there are high risks.

We propose two policy regimes for the implementation of the CcLTV regulation: one generic and one sector-specific. Under the generic regime, the authority adjusts the household and corporate LTV ratios to changes in aggregate credit and output; ${ }^{2}$ under the sector-specific regime, the authority adjusts

\footnotetext{
${ }^{2}$ The literature proposes several ways to implement the CcLTV. One frequently cited rule is the Taylor-type rule that says the policy instrument, the loan-to-value (LTV) ratio, should respond to variables such as credit-to-output ratio, credit, output, house prices or some combination of these variables (e.g., Rubio and Carrasco-Gallego; 2014). There is, however, no consensus on which variables to include in the policy rule.
} 
those ratios according to their specific sectoral credit conditions and output, with different intensities. ${ }^{3}$ We then compare the effectiveness of the two policy regimes in enhancing financial and macroeconomic stability. To measure financial stability we use the volatility of credit and house prices, and to measure macroeconomic stability we use the volatility of output, along the lines of Rubio and Carrasco-Gallego (2014) and Agénor and Pereira da Silva (2017). We pose the question whether the authority should use the generic CcLTV regime or the sector-specific CcLTV regime when implementing the CcLTV regulation in a setting where there are two types of borrowers: households, which borrow to finance consumption, and entrepreneurs, who borrow to finance production.

To do so, we develop a real business cycle dynamic stochastic general equilibrium (DSGE) model that incorporates the role of macro-prudential policy. Our model abstracts from nominal rigidities because in this paper we focus on the role of the CcLTV regulation in fostering financial and macroeconomic stability. The model is based on the framework of Iacoviello (2015), and populated by patient households (savers), banks, a macro-prudential authority and two types of borrower - household (impatient households) and corporate (entrepreneurs). The two types of borrower face borrowing constraints which state that the amount borrowed cannot exceed a certain fraction of the value of their collateral assets. The macroprudential authority adjusts its policy instrument, the loan-to-value ratio, in a counter-cyclical manner to foster financial and macroeconomic stability. The model is calibrated using South African data. It reproduces the cyclical moments of both the financial and real sectors fairly well. Given its simplicity and the small number of shocks considered, the model performs fairly satisfactorily in matching what we observe in the data.

Our key findings are as follows. We first derive the optimal rules for generic and sector-specific regimes and compare their effectiveness in minimising the macro-prudential authority's loss function (welfare loss). We find that the sector-specific regime is more effective than the generic regime in minimising welfare loss, particularly when the economy is hit by technology and financial shocks. However, when a housing demand shock hits the economy the generic regime is more effective in minimising welfare loss. For both regimes, therefore, optimal policy rules depend on the kind of shock. Both the corporate and the household CcLTV regimes require an aggressive reaction to credit following financial and housing demand shocks and only a moderate reaction to credit following a technology shock. Under the sectorspecific regime, the policy requires a stronger response to credit and output for the corporate CcLTV rule than for the household CcLTV rule. Compared to the baseline case (with constant LTV), both the generic and the sector-specific regimes are effective in minimising the volatility of the three key policy variables (credit, house prices and output), especially for credit. The sector-specific regime provides a higher degree of macroeconomic stability than the generic regime. This stabilisation effect becomes more significant when the economy faces financial and housing demand shocks.

The results of an impulse response analysis suggest that both the generic and the sector-specific regimes are effective in achieving the two objectives of macro-prudential policy: financial and macroeconomic stability. This is achieved mainly by attenuating the amplification effects of the borrowing

\footnotetext{
${ }^{3}$ By different intensities we mean that the policy coefficients on output in the household CcLTV rule and the corporate CcLTV rule are different.
} 
constraint channel. The effectiveness of both regimes is, however, shock dependent. When the economy faces a technology shock, their effectiveness is more or less the same. When the economy faces a financial shock, the sector-specific regime significantly outperforms the generic regime in attenuating the business cycle fluctuations, whereas the opposite is true when the economy is hit by a housing demand shock. When one sector of the credit market is hit by a financial shock, while the other sector is unaffected, the sector-specific regime plays an important role in stabilising fluctuations in the two credit market sectors and hence reducing the fluctuations in output. This implies that by adopting the sector-specific regime the macro-prudential authority can avoid the potential costs arising from implementing the generic regime and achieve both financial and macroeconomic stability in a more effective way. On the other hand, when both sectors of the credit market are hit by the same shock (the housing demand shock), the generic regime outperforms the sector-specific regime in achieving financial and macroeconomic stability. Since the CcLTV regulation works through the borrowing constraint channel and housing is used as a collateral asset for both types of borrowers, the shock affects both types of borrower in the same way. In this case the macro-prudential authority can implement the generic regime and not only achieve its two policy objectives but also minimise the welfare loss.

Importantly, these results indicate that when uncertainty occurs in the credit market, the macroprudential authority should first identify the source of the uncertainty. If the shock hits one sector of the credit market only, implementing the generic CcLTV regime can lead to an over-reaction in the other credit market sector and under-reaction in the sector that is hit by the shock. Instead of correcting financial imbalances in the shock-affected credit market sector, the generic regime exacerbates the effect of the shock on this shock-affected sector. We argue that this potential drawback of over-reaction in one sector of the credit market and under-reaction in the other can be eliminated by implementing the sector-specific regime. The regulator's flexibility in customising the CcLTV regulation according to the specific conditions of each credit market sector will enable the regulator to eliminate the imbalances in both sectors.

The efficiency policy frontiers under the two policy regimes present a clear trade-off between financial and macroeconomic stability, as the authority adjusts its preference between the two policy objectives. Our results show that the sector-specific CcLTV regime is more effective than the generic CcLTV regime in stabilising the volatility of credit and output and can deliver a larger reduction in output volatility at a lower cost of financial instability.

In terms of the implementation of the two CcLTV regimes, we find that the proposed CcLTV regimes have the potential to deliver on financial and macroeconomic stability mandates. However, this stabilising effect on financial stability diminishes if the regulator responds aggressively to changes in credit. Responses to changes in output can achieve financial stability only if the regulator responds moderately to changes in financial variables. However, regardless of whether the regulatory authority responds to changes in output aggressively or not, an aggressive response to changes in credit does not contribute to macroeconomic stability, whereas a moderate response to changes in credit has a significant impact.

The rest of the paper is organised as follows. Section 2 describes the model and Section 3 presents the calibration of the model. Section 4 describes the model's business cycle properties. Section 5 presents the 
optimal simple rules for implementing the generic and sector-specific CcLTV regimes and compares their effectiveness in minimising the loss function of the macro-prudential authority. Section 6 presents the impulse response functions analysis, Section 7 explains the efficiency policy frontier for the two CcLTV regimes, Section 8 describes the implementation of the optimal CcLTV and Section 9 concludes.

\section{The model}

Our model is a closed economy real business cycle model, featuring a banking sector, a housing market and the macro-prudential authority. Specifically, the model is built on the workhorse of Iacoviello (2015) and incorporates the role of the macro-prudential authority in implementing the CcLTV regulation to foster financial and macroeconomic stability. Since our focus is on the optimal design and the effectiveness of macro-prudential policy, our model abstracts from nominal rigidities.

The model features two types of households (patient and impatient), entrepreneurs, the bank and the macro-prudential authority. Households work (i.e. supply labour), and consume the final output (consumption goods) and housing. Patient households are the savers in the economy and provide the bank with savings deposits. Impatient households are one type of borrower in the economy, using their housing as a collateral asset to secure credit from the bank. Entrepreneurs are the other type of borrower in the economy, producing the final output using household labour and housing as inputs. To finance their production, entrepreneurs borrow funds from the bank against their stock of housing. The bank mediates funds between savers (patient households) and borrowers (impatient households and entrepreneurs). The macro-prudential authority is responsible for financial stability using the CcLTV regulation. While there is no consensus in the literature on which variables to include in the macro-prudential policy rules, we assume that the authority adjusts the LTV ratios to changes in credit and output. This kind of policy rule is consistent with the main objective of macro-prudential policy: to protect the financial system from the risks associated with excessive credit growth without compromising macroeconomic stability. For the purpose of our study, we consider two CcLTV regimes, generic and sector-specific.

\subsection{Patient Households (Savers)}

The representative patient household chooses real consumption $\left(C_{s, t}\right)$, housing $\left(H_{s, t}\right)$ and leisure $\left(1-N_{s, t}\right)$ to maximise the expected discounted lifetime utility:

$$
E_{0} \sum_{t=0}^{\infty} \beta_{s}^{t}\left[\left(1-\eta_{s}\right) \log \left(C_{s, t}-\eta_{s} C_{s, t-1}\right)+j A_{t} \log \left(H_{s, t}\right)+\tau \log \left(1-N_{s, t}\right)\right],
$$

where $E_{0}$ and $\beta_{s} \in(0,1)$ are the expectation operator and the household's subjective discount factor, respectively. Consumption appears in the utility function relative to external habit formation, with $\eta_{s}$ measuring degree of habit persistence. In line with Iacoviello (2015) and Guerrieri and Iacoviello (2017), the scaling factor $1-\eta_{s}$ ensures that the marginal utility of consumption is independent of the habit parameter in the steady state. $j$ and $\tau$ are weights of housing and leisure in the utility function, respectively. $A_{t}$ is the housing demand shock, which evolves according to the following law of motion:

$$
\log \left(A_{t}\right)=\rho_{a} \log \left(A_{t-1}\right)+\xi_{a, t},
$$


where $\rho_{a}$ is a parameter representing the persistence of the shock. $\xi_{a, t} \sim$ i.i.d.N $\left(0, \sigma_{a}^{2}\right)$ is a white noise process, normally distributed with mean zero and variance $\sigma_{a}^{2}$. The housing demand shock captures exogenous factors that shift the household's preference and demand for housing. Iacoviello (2005) suggests that the housing demand shock offers a parsimonious way to analyse exogenous disturbances to housing prices.

In each period, the household begins with housing stock $\left(H_{s, t-1}\right)$ and savings deposits $\left(D_{t-1}\right)$ coming to mature. The household supplies labour to entrepreneurs and receives real wage rate $W_{s, t} . R_{d, t}$ is the real gross return on a one-period risk-free deposit and $q_{t}$ is the relative price of housing (in units of consumption). The household's budget constraint is given by:

$$
C_{s, t}+D_{t}+q_{t}\left(H_{s, t}-H_{s, t-1}\right)=W_{s, t} N_{s, t}+R_{d, t-1} D_{t-1}
$$

Let $U_{C s, t}=\frac{1-\eta_{s}}{C_{s, t}-\eta_{s} C_{s, t-1}}$ be the marginal utility of consumption. The first order conditions for the household's problem are as follows:

$$
\begin{gathered}
1=\beta_{s} E_{t} \frac{U_{C s, t+1}}{U_{C s, t}} R_{d, t}, \\
q_{t}=j \frac{A_{t}}{H_{s, t} U_{C s, t}}+\beta_{s} E_{t}\left(\frac{U_{C s, t+1}}{U_{C s, t}}\right) q_{t+1} \\
W_{s, t}=\frac{\tau}{\left(1-N_{s, t}\right) U_{C s, t}} .
\end{gathered}
$$

Eq. (4) is the standard consumption Euler equation. Asset pricing Eq. (5) for housing equates the marginal cost of housing to its marginal benefit. For the household the marginal benefit of housing is given by the direct utility benefit of consuming one extra unit of housing in units of consumption plus the present discounted value of housing. Eq. (5) can also be regarded as household's demand for housing. The household's labour supply condition Eq. (6) equates the real wage rate to the marginal rate of substitution between consumption and leisure.

\section{$2.2 \quad$ Impatient Households (Borrowers)}

Like the patient household, the representative impatient household maximises the expected discounted lifetime utility:

$$
E_{0} \sum_{t=0}^{\infty} \beta_{b}^{t}\left[\left(1-\eta_{b}\right) \log \left(C_{b, t}-\eta_{b} C_{b, t-1}\right)+j A_{t} \log \left(H_{b, t}\right)+\tau \log \left(1-N_{b, t}\right)\right],
$$

where $\beta_{b}$ is the household's subjective discount factor and $\beta_{b}<\beta_{s} . C_{b, t}$ is the household's real consumption, $H_{b, t}$ is its housing stock and and $N_{b, t}$ is its labour supply. Its budget constraint is given by:

$$
C_{b, t}+R_{b, t-1} L_{b, t-1}+q_{t}\left(H_{b, t}-H_{b, t-1}\right)=W_{b, t} N_{b, t}+L_{b, t}+\zeta_{b, t},
$$

where $L_{b, t}$ is the bank's loan to the household which accrues a real gross interest rate of $R_{b, t} . W_{b, t}$ is real wage rate for the household. Following Iacoviello (2015), we introduce an exogenous loan loss shock $\zeta_{b, t} \cdot{ }^{4}$ Intuitively, this shock can be thought of as a partial default by the household on its loan. For the

\footnotetext{
${ }^{4}$ Loan losses are scaled by steady-state value of bank loans to impatient households analogous to Iacoviello (2015).
} 
household, a loan default is an indirect increase in wealth. By paying less than the contracted amount, the household can spend more than it anticipated. The same shock appears with a negative sign in the bank's budget constraint. The shock evolves according to the following law of motion:

$$
\zeta_{b, t}=\rho_{\zeta} \zeta_{b, t-1}+\xi_{\zeta, t}
$$

where $\rho_{\zeta}$ is the parameter representing the persistence of the shock. $\xi_{\zeta, t} \sim i . i . d . N\left(0, \sigma_{\zeta}^{2}\right)$ is the white noise process, normally distributed with mean zero and variance $\sigma_{\zeta}^{2}$.

The household faces a credit constraint that limits the amount borrowed to a fraction $m_{b, t}$ of the expected value the housing:

$$
L_{b, t} \leq m_{b, t} E_{t}\left(\frac{q_{t+1}}{R_{b, t}} H_{b, t}\right)
$$

$m_{b, t} \in(0,1)$ is the loan-to-value (LTV) ratio for the impatient household. The LTV ratio is determined by the macro-prudential authority as its regulatory instrument.

Let $U_{C b, t}=\frac{1-\eta_{b}}{C_{b, t}-\eta_{b} C_{b, t-1}}$ be the marginal utility of consumption and $\lambda_{b, t}$ be the multiplier on the borrowing constraint. The first order conditions which define the household's problem are:

$$
\begin{gathered}
1=\beta_{b} E_{t} \frac{U_{C b, t+1}}{U_{C b, t}} R_{b, t}+\frac{\lambda_{b, t}}{U_{C b, t}}, \\
q_{t}=j \frac{A_{t}}{H_{b, t} U_{C b, t}}+\beta_{b} E_{t}\left(\frac{U_{C b, t+1}}{U_{C b, t}}\right) q_{t+1}+m_{b, t}\left(\lambda_{b, t} / U_{C b, t}\right) E_{t} \frac{q_{t+1}}{R_{b, t}} \\
W_{b, t}=\frac{\tau}{\left(1-N_{b, t}\right) U_{C b, t}} .
\end{gathered}
$$

Eq. (11) represents the household's demand for a bank loan. It differs from the standard Euler equation because of the borrowing constraint. Asset pricing Eq. (12) for housing equates the marginal cost of housing to its marginal benefit. For the household, the marginal benefit of housing is given by the direct utility benefit of consuming one extra unit of housing service in units of consumption (the marginal rate of substitution between housing and consumption) plus the present discounted value of housing (the benefit the housing provides in the next period as a store of wealth). Eq. (12) is the household's demand for housing. Eq. (13) is the household's labour supply condition.

\section{$2.3 \quad$ Entrepreneurs}

Entrepreneurs produce final output $\left(Y_{t}\right)$ using two types of household labour supply $\left(N_{s, t}\right.$ and $\left.N_{b, t}\right)$ and housing $\left(H_{e, t}\right)$ as inputs. The representative entrepreneur maximises the expected discounted lifetime utility:

$$
E_{0} \sum_{t=0}^{\infty} \beta_{e}^{t}\left(1-\eta_{e}\right) \log \left(C_{e, t}-\eta_{e} C_{e, t-1}\right),
$$

where $\beta_{e}<\beta_{s} . C_{e, t}$ is the entrepreneur's real consumption, which can be regarded as profits or dividends. Therefore, $\eta_{e} C_{e, t-1}$ captures some form of dividend smoothing in line with Liu et al. (2013). Liu et al. (2013) note that this form of dividend smoothing is essential to adequately explain the dynamics between asset prices and real variables. The budget constraint for the entrepreneur is given by:

$$
C_{e, t}+q_{t}\left(H_{e, t}-H_{e, t-1}\right)+R_{e, t} L_{e, t-1}+W_{s, t} N_{s, t}+W_{b, t} N_{b, t}=Y_{t}+L_{e, t}+\zeta_{e, t},
$$


where $N_{s, t}$ and $N_{b, t}$ are patient and impatient households' labour supply, respectively. $L_{e, t}$ is the amount borrowed from the bank, which accrues a real gross interest rate of $R_{e, t}$. The term $\zeta_{e, t}$ captures an exogenous loan repayment shock. ${ }^{5}$ Like the impatient household's loan loss shock, the shock represents an indirect increase in wealth in the event of default. The shock evolves according to the following law of motion:

$$
\zeta_{e, t}=\rho_{\zeta} \zeta_{e, t-1}+\xi_{\zeta, t},
$$

where $\rho_{\zeta}$ is the persistence of the shock. $\xi_{\zeta, t} \sim$ i.i.d.N $\left(0, \sigma_{\zeta}^{2}\right)$ is the white noise process, normally distributed with mean zero and variance $\sigma_{\zeta}^{2}$.

Production technology is given by a constant return to scale Cobb-Douglas production function:

$$
Y_{t}=Z_{t} H_{e, t-1}^{\nu}\left[N_{s, t}^{1-\sigma} N_{b, t}^{\sigma}\right]^{1-\nu},
$$

where the parameter $\nu \in(0,1)$ is the elasticity of output with respect to housing and $\sigma \in(0,1)$ measures the impatient households' labour output share. ${ }^{6}$ Technology shock $\left(Z_{t}\right)$ evolves according to the following law of motion:

$$
\log \left(Z_{t}\right)=\rho_{z} \log \left(Z_{t-1}\right)+\xi_{z, t},
$$

where $\rho_{z}$ is the parameter representing the persistence of the shock. $\xi_{z, t} \sim$ i.i.d.N $\left(0, \sigma_{z}^{2}\right)$ is the white noise process, normally distributed with mean zero and variance $\sigma_{z}^{2}$.

The entrepreneur also faces the borrowing constraint:

$$
L_{e, t} \leq m_{e, t} E_{t}\left(\frac{q_{t+1}}{R_{e, t+1}} H_{e, t}\right) .
$$

Eq. (19) suggests that the total amount of credit the entrepreneur can secure from the bank cannot exceed a fraction $m_{e, t}$ of the expected market value of the entrepreneur's collateral assets. $m_{e, t} \in(0,1)$ represents the LTV ratio for the entrepreneur (the corporate LTV ratio) and is determined by the macro-prudential authority as its regulatory instrument. ${ }^{7}$ The dual role of housing as collateral asset and productive input is widely acknowledged in the DSGE literature (see for e.g., Iacoviello; 2005, Chaney et al.; 2012, Liu et al.; 2013, Minetti and Peng; 2013) ${ }^{8}$. As we show later, the condition $\beta_{e}<\beta_{s}$ ensures that the borrowing constraint Eq. (19) is binding in the neighbourhood of the steady-state.

Let $U_{C e, t}=\frac{1-\eta_{e}}{C_{e, t}-\eta_{e} C_{e, t-1}}$ be the marginal utility of consumption and $\lambda_{e, t}$ be the multiplier on the borrowing constraint Eq. (19). The first order conditions which define the entrepreneur's problem are as follows:

$$
\begin{gathered}
q_{t}=\beta_{e} E_{t} \frac{U_{C e, t+1}}{U_{C e, t}}\left(\nu \frac{Y_{t+1}}{H_{e, t}}+q_{t+1}\right)+m_{e, t}\left(\lambda_{e, t} / U_{C e, t}\right) E_{t} \frac{q_{t+1}}{R_{e, t+1}}, \\
W_{s, t} N_{s, t}=(1-\sigma)(1-\nu) Y_{t},
\end{gathered}
$$

\footnotetext{
${ }^{5}$ Entrepreneur loan losses are scaled by steady-state value of bank loans to entrepreneurs analogous to Iacoviello (2015).

${ }^{6}$ As in Iacoviello (2015), the production technology assumes that the two types of labour (patient and impatient households) are complements. This assumption ensures that we obtain a close-form solution for the steady state of the model (Mendicino and Punzi; 2014).

${ }^{7}$ Throughout the paper, corporate LTV ratio means LTV ratio for entrepreneurs.

${ }^{8}$ Using housing stock as one production input provides a motive for entrepreneurs to hold housing stock, which is in turn being used as a collateral asset for securing bank credit. This also allows us to analyse the impact of house prices (one of our measures of financial stability) on the entrepreneur's investment and production decisions.
} 


$$
\begin{gathered}
W_{b, t} N_{b, t}=\sigma(1-\nu) Y_{t}, \\
1=\lambda_{e, t} / U_{C e, t}+\beta_{e} E_{t} \frac{U_{C e, t+1}}{U_{C e, t}} R_{e, t+1} .
\end{gathered}
$$

Eq. (20) represents the entrepreneur's demand for housing. It equates the marginal cost of one extra unit of housing (price of housing) to its marginal benefits. For the entrepreneur, the marginal benefits of housing are given by the present discounted value of the next period's real return on housing plus the benefit of housing as a collateral asset for securing credit. The entrepreneur's real return on housing is given by the marginal product of the housing and the future resale value of the housing. In essence, condition Eq. (20) equates the current price of housing to its expected resale value plus the pay-off from holding this asset for one period (given by the marginal productivity of housing and its ability to serve as collateral). Eqs. (21) and (22) are labour demand conditions. Eq. (23) is the asset pricing equation for the entrepreneur's demand for credit.

\subsection{The bank}

The bank is a financial intermediary that mediates funds between savers (patient households) and borrowers (impatient households and entrepreneurs). The representative bank chooses real consumption $\left(C_{f, t}\right)$ to maximise the expected discounted lifetime utility:

$$
E_{0} \sum_{t=0}^{\infty} \beta_{f}^{t}\left(1-\eta_{f}\right) \log \left(C_{f, t}-\eta_{f} C_{f, t-1}\right),
$$

where $\beta_{f}$ is the bank's subjective discount factor. Note that $C_{f, t}$ can be interpreted as dividend payments from the bank, which are assumed to be fully consumed by the bank. $\eta_{f} C_{f, t-1}$ represents some form of dividend smoothing. The bank's budget constraint is given by:

$$
C_{f, t}+R_{d, t-1} D_{t-1}+L_{b, t}+L_{e, t}+A C_{b f, t}+A C_{e f, t}=D_{t}+R_{b, t-1} L_{b, t-1}+R_{e, t} L_{e, t-1}-\zeta_{t},
$$

where $D_{t}$ is the household's deposits. $L_{b, t}$ and $L_{e, t}$ are bank lending to impatient households and entrepreneurs, respectively. $A C_{b f, t}=\frac{\phi_{b f}}{2} \frac{\left(L_{b, t}-L_{b, t-1}\right)^{2}}{L_{b}}$ and $A C_{e f, t}=\frac{\phi_{e f}}{2} \frac{\left(L_{e, t}-L_{e, t-1}\right)^{2}}{L_{e}}$ are quadratic loan portfolio adjustment costs associated with household and entrepreneur loans, respectively. $\zeta_{t}=\zeta_{b, t}+\zeta_{e, t}$ is the loan repayment shock. This represents loan losses that the bank incurs when impatient households and entrepreneurs default on their loans. From the bank's perspective, loan losses also represent a shock to their net worth. An increase in loan losses reduces the bank's profits and impairs its balance sheet. This results in a decline in the bank's capital.

The bank is also subject to capital requirement in line with the Basel capital regulations. Specifically, the bank is required to hold a certain amount of bank capital that covers, at least, a specified fraction of its assets (loans). Let $B K_{t}=L_{t}-E_{t} \zeta_{t+1}-D_{t}$ be the bank's capital. The capital requirement constraint is given $b^{9}$ :

$$
\frac{L_{t}-E_{t} \zeta_{t+1}-D_{t}}{w_{b}\left(L_{b, t}-E_{t} \zeta_{b, t+1}\right)+w_{e}\left(L_{e, t}-E_{t} \zeta_{e, t+1}\right)} \geq \kappa
$$

\footnotetext{
${ }^{9}$ For simplicity, the paper does not distinguish between required capital and excess capital held voluntarily by South African banks. South African banks consistently maintain capital adequacy ratios over the regulatory requirements. Over
} 
where $\kappa \in(0,1)$ is capital requirement ratio and $L_{t}=L_{b, t}+L_{e, t}$ is the aggregate credit. $E_{t} \zeta_{t+1}$ represents allowance for expected loan losses. $w_{b}$ and $w_{e}$ denote risk weights on household and entrepreneur borrowing, respectively. These parameters capture different degrees of risk associated with household and entrepreneur borrowing. The capital requirement constraint (26) can be rewritten as a borrowing constraint as follows:

$$
D_{t} \leq\left(1-w_{e} \kappa\right)\left(L_{e, t}-E_{t} \zeta_{e, t+1}\right)+\left(1-w_{b} \kappa\right)\left(L_{b, t}-E_{t} \zeta_{b, t+1}\right) .
$$

Eq. (27) states that the amount that the bank can take as a deposit from households cannot exceed a weighted sum of the bank's assets net of the expected loan losses, where the weights on the two classes of the bank's assets are given by $\left(1-w_{i} \kappa\right)$, for all $i=\{b, e\}$. The capital requirement constraint limits the extent to which the bank can take on leverage. The assumption is that the bank is more impatient than the patient household; that is $\beta_{f}<\beta_{s}$, ensures that the borrowing constraint (27) is binding in the steady state. In the absence of this assumption, the bank may find that it is optimal to postpone current consumption indefinitely and accumulate capital to the point where the capital requirement constraint does not have force.

Let $U_{C f, t}=\frac{1-\eta_{f}}{C_{f, t}-\eta_{f} C_{f, t-1}}$ be the marginal utility of consumption and $\lambda_{f, t}$ be the multiplier on the bank's borrowing constraint (27). The bank's optimal condition for deposits and credit to households and entrepreneurs are given by:

$$
\begin{gathered}
\beta_{f} E_{t} \frac{U_{C f, t+1}}{U_{C f, t}} R_{d, t}=1-\lambda_{f, t} / U_{C f, t}, \\
\beta_{f} E_{t} \frac{U_{C f, t+1}}{U_{C f, t}} R_{b, t}=1-\left(1-w_{b} \kappa\right)\left(\lambda_{f, t} / U_{C f, t}\right)+\frac{\phi_{b f}}{L_{b}}\left(L_{b, t}-L_{b, t-1}\right), \\
\beta_{f} E_{t} \frac{U_{C f, t+1}}{U_{C f, t}} R_{e, t+1}=1-\left(1-w_{e} \kappa\right)\left(\lambda_{f, t} / U_{C f, t}\right)+\frac{\phi_{e f}}{L_{e}}\left(L_{e, t}-L_{e, t-1}\right) .
\end{gathered}
$$

The banks' demand for deposits (28) equates the current pay-off from taking one extra unit of deposit from the patient household to the discounted cost of raising such deposits. Eqs. (29) and (30) equate the present discounted pay-off of providing one extra unit of credit (to impatient households and entrepreneurs) to the cost of providing such credit.

From Eqs. (28) to (30), the evolution of interest rate spreads are given by:

$$
\begin{gathered}
R_{b, t}-R_{d, t}=\frac{1}{\beta_{f}} E_{t} \frac{U_{C f, t}}{U_{C f, t+1}}\left[w_{b} \kappa\left(\lambda_{f, t} / U_{C f, t}\right)+\frac{\phi_{b f}}{L_{b}}\left(L_{b, t}-L_{b, t-1}\right)\right], \\
R_{e, t+1}-R_{d, t}=\frac{1}{\beta_{f}} E_{t} \frac{U_{C f, t}}{U_{C f, t+1}}\left[w_{e} \kappa\left(\lambda_{f, t} / U_{C f, t}\right)+\frac{\phi_{e f}}{L_{e}}\left(L_{e, t}-L_{e, t-1}\right)\right] .
\end{gathered}
$$

In the steady state, Eqs. (4) and (28) suggest that the bank's borrowing constraint (27) (and hence capital requirement constraint) holds with equality as long as $\beta_{f}<\beta_{s}$. Formally:

$$
\lambda_{f} C_{f}=\frac{\beta_{s}-\beta_{f}}{\beta_{s}}>0,
$$

the period 2008 - 2015, the average amount of excess bank capital held by SA banks is estimated at $4 \%$ of risk weighted assets (Liu and Seeiso; 2012) 
so long as,

$$
\beta_{f}<\beta_{s} .
$$

Furthermore, if conditions (33) and (34) hold there will be a positive spread between the lending rate and deposit rate. That is, from Eqs. (31) to (34), it follows that:

$$
\begin{aligned}
& R_{b}-R_{d}=\frac{w_{b} \kappa\left(\beta_{s}-\beta_{f}\right)}{\beta_{s} \beta_{f}}>0, \\
& R_{e}-R_{d}=\frac{w_{e} \kappa\left(\beta_{s}-\beta_{f}\right)}{\beta_{s} \beta_{f}}>0 .
\end{aligned}
$$

Given the lending rate $R_{b}$, Eq. (11) suggests that the necessary condition for impatient household's borrowing constraint (10) to hold with equality (that is, $\left(\lambda_{b} C_{b}\right)>0$ ) is:

$$
\frac{1}{\beta_{b}}>R_{b} \text {. }
$$

Alternatively, using Eqs. (29) and (33), the condition for impatient household's borrowing constraint to hold with equality requires that:

$$
\frac{1}{\beta_{b}}>\frac{w_{b} \kappa}{\beta_{f}}+\frac{\left(1-w_{b} \kappa\right)}{\beta_{s}} .
$$

Similarly, from Eq. (23), it requires that:

$$
\frac{1}{\beta_{e}}>R_{e},
$$

or, from equations Eqs. (30) and (33) it follows that:

$$
\frac{1}{\beta_{e}}>\frac{w_{e} \kappa}{\beta_{f}}+\frac{\left(1-w_{b} \kappa\right)}{\beta_{s}},
$$

for an entrepreneur's borrowing constraint (19) to hold with equality.

\subsection{Macro-prudential policies}

The authority uses the counter-cyclical loan-to-value (CcLTV) regulation as its macro-prudential tool - adjusting the LTV ratio to changes in credit and output in a counter-cyclical manner. The CcLTV regulation requires the authority to decrease the LTV ratios in an upswing of the business and credit cycle, thus tightening the borrowing constraints and restraining credit growth and leverage in the creditdependent sector. In a downswing of the cycle, the regulation requires the authority to increase the LTV ratios, thus relaxing the borrowing constraints to encourage credit growth. In this way, the authority prevents excessive fluctuation in credit and contains the build-up of systemic risk in the financial sector and the spillover of financial vulnerabilities to the real sector.

We consider generic and sector-specific CcLTV policy regimes. Under the generic regime, the authority does not differentiate between the two credit market sectors and adjusts both household and corporate LTV ratios to changes in aggregate credit and output as follows:

$$
m_{i, t}=m_{i}\left(\frac{L_{t}}{L}\right)^{-\chi_{l, m}}\left(\frac{Y_{t}}{Y}\right)^{-\chi_{y, m}}, \forall i=\{b, e\},
$$

where $m_{i}$ is the steady-state value of the LTV ratio, $L$ and $Y$ are the steady-state values of aggregate credit and output, respectively. $\chi_{l, m} \geq 0$ and $\chi_{y, m} \geq 0$ measure the response of the LTV ratio to deviations of credit and output from their steady states, respectively. 
Under the sector-specific regime, the authority differentiates between the two credit market sectors and adjusts the two LTV ratios to changes in sectoral credit. The LTV ratios of the two sectors respond to changes in output with different intensities:

$$
m_{i, t}=m_{i}\left(\frac{L_{i, t}}{L_{i}}\right)^{-\chi_{l, m_{i}}}\left(\frac{Y_{t}}{Y}\right)^{-\chi_{y, m_{i}}}, \forall i=\{b, e\}
$$

where $\chi_{l, m i} \geq 0$ and $\chi_{y, m i} \geq 0$ measure the responses of the LTV ratios to deviations of sectoral credit and output from their steady states, respectively.

The CcLTV regulation requires the authority to decrease the LTV ratios in an upswing of the business and credit cycle, thus tightening the borrowing constraints and restraining credit growth and leverage in the credit-dependent sector. In a downswing of the cycle, the regulation requires the authority to increase the LTV ratios, thus relaxing the borrowing constraints to encourage credit growth. In this way, the authority prevents excessive fluctuation in credit and contains the build-up of systemic risk in the financial sector and the spillover of financial vulnerabilities to the real sector.

\subsection{Market clearing conditions and equilibrium}

The economy's aggregate resource constraint becomes:

$$
Y_{t}=C_{s, t}+C_{b, t}+C_{e, t}+C_{f, t}+A d j_{t}
$$

where $A d j_{t}=A C_{b f, t}+A C_{e f, t}$.

The housing market clearing condition requires:

$$
H_{s, t}+H_{b, t}+H_{e, t}=1
$$

The aggregate supply of credit is given by:

$$
L_{t}=L_{b, t}+L_{e, t}
$$

\section{Calibration}

We calibrate our model to the South African economy using quarterly data over the sample period 1994Q1 to 2016Q4. ${ }^{10}$ Some of the parameters are calibrated using real data to match the steady-state conditions of the model and others are borrowed from the literature.

Table 1 shows the calibrated parameter values for the model. The discount factor for patient households (savers) is set at $\beta_{s}=0.99$ in line with the literature. Following Iacoviello (2015) and Minetti and Peng (2013), impatient households' and entrepreneurs' discount factors are calibrated at $\beta_{b}=\beta_{e}=0.94$, which ensure that the borrowing constraints for both are binding in the neighbourhood of the steady state.

The weight on leisure in the households' utility function is set at $\tau=2$, in line with the literature. This value implies that households devote approximately one third of their time to work. The impatient

\footnotetext{
${ }^{10}$ Data source: South African Reserve Bank.
} 
Table 1: Calibrated parameters.

\begin{tabular}{|c|c|c|c|c|c|}
\hline Parameter & Symbol & Value & Parameter & Symbol & Value \\
\hline Discount factor (patient $\mathrm{HH}$ ) & $\beta_{s}$ & 0.99 & Impatient HH's income share & $\sigma$ & 0.31 \\
\hline Discount factor (impatient $\mathrm{HH}$ ) & $\beta_{b}$ & 0.94 & Labor supply parameter & $\tau$ & 2 \\
\hline Discount factor (Entrep.) & $\beta_{f}$ & 0.94 & Loan to $\mathrm{HH}$ adj. cost, Bank & $\phi_{b f}$ & 0.25 \\
\hline Discount factor (Bank) & $\beta_{b}$ & 0.945 & Loan to Entrep. adj. cost, Bank & $\phi_{e f}$ & 0.05 \\
\hline Habit persistence, $i=\{s, b, e, f\}$ & $\eta_{i}$ & 0.70 & Risk weight (Impatient HH's loan) & $w_{b}$ & 1 \\
\hline Housing preference & $j$ & 0.10 & Risk weights (Entrep. loan) & $w_{e}$ & 1 \\
\hline Steady state LTV ratio, impatient $\mathrm{HH}$ & $m_{b}$ & 0.90 & Autocorr. technology shock & $\rho_{z}$ & 0.95 \\
\hline Steady state LTV ratio, Entrep. & $m_{e}$ & 0.70 & Autocorr. housing demand shock & $\rho_{a}$ & 0.97 \\
\hline Steady state capital requirement ratio & $\kappa$ & 0.105 & Autocorr. financial (loan loss) shock, $i=\{b, e\}$ & $\rho_{\zeta_{i}}$ & 0.90 \\
\hline Housing share in production & $\nu$ & 0.1 & & & \\
\hline
\end{tabular}

HH - Household; Entrep. - Entrepreneur.

household's labour income share is calibrated at $\sigma=0.31$, broadly in line with the estimated value of 0.27 in Gupta and Sun (2016) for the South African economy. Parameters governing habit persistence and loan portfolio adjustment costs are calibrated as follows. Habit persistence for all agents is set at $\eta_{i}=0.7$, which is broadly in line with the literature. The bank's loan portfolio adjustment cost parameters are set at $\phi_{b f}=0.25$ and $\phi_{e f}=0.05$ for household loans and entrepreneur loans, respectively.

The share of housing in production is set at $\nu=0.1$ in the ballpark of the values widely used in the literature for emerging market economies (EMEs) (e.g., Iacoviello and Minetti; 2006). Housing weight in the utility functions is calibrated at $j=0.1$. The choice of these values pins down steady state ratio of real estate wealth to output at 2.8 (annualized), of which 2.0 is residential real estate wealth and 0.8 is commercial real estate wealth. These ratios are fairly in line with the South African data on housing wealth. ${ }^{11}$

The steady state leverage ratios for impatient households and entrepreneurs are based on the South Africa's credit market data over the sample period. LTV ratio for impatient households is set at $m_{b}=0.9$. This value is fairly consistent with the minimum down-payment that South African banks require for providing home loans. For the entrepreneur, LTV is set at $m_{e}=0.7$. These values are also well within the observed maximum LTV ratios for a first-time mortgage buyer in an EME like South Africa (see, e.g. IMF; 2011). These values imply that the steady-state ratio of household mortgage loans to total output is approximately 0.33 while the ratio of corporate credit to output is 0.54 , consistent with the South African credit market data.

The bank's capital requirement ratio is set to mimic the Basel III bank capital requirements. It is calibrated at $\kappa=0.105$. The risk weights assigned on household and entrepreneur loans are both set at $w_{b}=w_{e}=1$. The discount factor for the bank is set at $\beta_{f}=0.95$. This value is lower than the patient households' discount factor $\left(\beta_{s}\right)$, which satisfies condition (34), which is required for the capital requirement constraint to hold with equality in steady state. Together with the impatient

\footnotetext{
${ }^{11}$ The 2016 Property Sector Charter Council's (PSCC) report suggests that the share of South Africa's housing wealth to total output is approximately $2.3,75$ percent of which is constituted of residential housing wealth while the remaining is commercial housing wealth. Source: http://www.sacommercialpropnews.co.za/property-investment/8211-sa-propertysector-volumes-to-r5-8-trillion.html.
} 
households' and entrepreneurs' discount factors, these values also guarantee that impatient households' and entrepreneurs' borrowing constraints are binding in the steady state. ${ }^{12}$ Furthermore, they imply a 200 basis points spread between the lending rate and the deposit rate, which is broadly in line with the SA interest rate data.

Lastly, the persistence of the shocks is calibrated as follows. The autocorrelation coefficients for technology and housing demand shocks are set at $\rho_{z}=0.95$ and $\rho_{a}=0.97$ respectively, consistent with Liu and Gupta (2007) and the estimated value in Gupta and Sun (2016). The choice of a highly persistent housing demand shock is also consistent with the DSGE literature. See for example Lambertini et al. (2013), Iacoviello (2015) and Brzoza-Brzezina et al. (2015). The persistence of the financial (loan loss) shock is set at $\rho_{\zeta_{i}}=0.90$ based on the estimates in Iacoviello (2015).

\section{Business cycle properties}

In this section we assess the model's ability to reproduce the facts of the South African data observed over the period 1994Q1-2016Q4. ${ }^{13}$ Table 2 shows the standard deviations of the main variables and their correlations with output as implied by the model and as calculated from the data. Model 1 shows the second moments generated from the technology shock and Model 2 shows those generated from the technology, housing demand and financial (household and corporate loan loss) shocks to capture the housing and financial market properties of the data. ${ }^{14}$

The results show that Model 1 (technology shock only) reproduces the cyclical moments of the real sector fairly well. The volatility of the output generated from the model is in line with the data. However, the model somewhat underestimates the volatilities of household consumption and house prices. The model is able to account for the fact that house prices are more volatile than output, but marginally fails to account for the fact that household consumption is also more volatile than output. Model 1 reproduces the positive correlation of consumption and house prices with output, but overestimates these correlations. Consistent with the data, the model generates stronger co-movement between output and household consumption than between output and house prices.

Model 1 also does a reasonably good job of matching the cyclical moments of the banking sector. It performs well in replicating the standard deviations of deposits, household and corporate loans, which are fairly in line with the data. The model is able to produce a good account of the fact that these variables are more volatile than output, whereas the lending rates are less volatile than output. Furthermore,

\footnotetext{
${ }^{12}$ See sub-section 2.4 for a detailed discussion on the conditions for the capital requirement constraint and impatient households' and entrepreneurs' borrowing constraints to hold with equality in steady state.

${ }^{13}$ Data on household and corporate lending rates are only available from 2008Q1. To back-cast the missing data for the two lending rates over the period 1994Q1-2008Q4, we first run regressions of the household and the corporate lending rates (each) on a constant and the prime lending rate for the period 2008Q1-2016Q4 and then use the resulting regression coefficients together with the actual prime lending rate data.

${ }^{14}$ In line with the literature, we assume that the standard deviation of the housing demand shock is slightly larger than that of the technology shock while that of the financial shock is slightly smaller. In particular, we experiment with the values of $\sigma_{z}=0.01, \sigma_{a}=0.035$ and $\sigma_{\zeta_{i}}=0.0025$ for all $i=\{b, e\}$. See for example Lambertini et al. (2013), Liu et al. (2013), Rubio and Carrasco-Gallego (2014), Brzoza-Brzezina et al. (2015), Iacoviello (2015) and Ravn (2016).
} 
Table 2: Business cycle properties.

\begin{tabular}{|c|c|c|c|c|c|c|}
\hline \multirow[b]{2}{*}{ Variable } & \multicolumn{3}{|c|}{ Standard deviation (\%) } & \multicolumn{3}{|c|}{ Correlation with output } \\
\hline & Data & Model 1 & Model 2 & Data & Model 1 & Model 2 \\
\hline Output & 1.16 & 1.15 & 1.19 & 1.00 & 1.00 & 1.00 \\
\hline Household consumption & 1.76 & 1.09 & 1.10 & 0.81 & 1.00 & 0.98 \\
\hline House prices & 4.59 & 1.66 & 2.19 & 0.30 & 0.88 & 0.77 \\
\hline Household deposits & 2.77 & 3.26 & 4.60 & 0.23 & 0.84 & 0.71 \\
\hline Household loans & 4.08 & 3.28 & 4.55 & 0.51 & 0.84 & 0.68 \\
\hline Corporate loans & 4.81 & 3.26 & 4.70 & 0.31 & 0.85 & 0.70 \\
\hline Household lending rate & 0.73 & 1.10 & 1.45 & -0.19 & -0.19 & -0.19 \\
\hline Corporate lending rate & 0.60 & 0.69 & 0.96 & -0.26 & -0.09 & -0.10 \\
\hline
\end{tabular}

Note. Model 1 is simulated with a technology shock only. Model 2 is simulated with technology, financial (loan loss) and housing demand shocks. Except for the lending rates, all variables are log-transformed and de-trended using the Hodrick-Prescott (HP) filter. Source: Data are from

South African Reserve Bank.

the model replicates the pro-cyclicality of deposits and the two types of loans, and does a good job of mimicking the negative correlation between the output and the lending rates.

When we simulate the model with all three shocks (Model 2), the results are improved. The inclusion of the housing demand and financial (loan loss) shocks increases the volatility of all variables and reduces the correlation of these variables with output. Model 2 is better able to reproduce the volatility of house prices and household and corporate loans. It is able to account for the fact that corporate loans are slightly more volatile than household loans as revealed in the data. However, it slightly exaggerates the volatility of the lending rates. Given its simplicity and the small number of shocks considered, the model performs fairly satisfactorily in matching what we observed in the data.

\section{Optimal CcLTV rules: generic versus sector-specific}

In this section we derive the optimal rules for generic and sector-specific CcLTV regimes and compare their effectiveness in fostering financial and macroeconomic stability. Following the literature (e.g., Angelini et al.; 2014), we define the macro-prudential authority's loss function as follows: ${ }^{15}$

$$
\mathcal{L}_{m p}=\lambda_{l} \sigma_{l}^{2}+\lambda_{q} \sigma_{q}^{2}+\lambda_{y} \sigma_{y}^{2}
$$

where $\sigma_{l}^{2}, \sigma_{q}^{2}$ and $\sigma_{y}^{2}$ are the unconditional variances of credit, house prices and output, respectively. The parameters $\lambda_{l} \geq 0, \lambda_{q} \geq 0$ and $\lambda_{y} \geq 0$ represent their weights in the loss function.

The loss function (46) implies that the macro-prudential authority strives to achieve financial stability (measured by fluctuations in credit and house prices) without compromising macroeconomic stability (measured by fluctuations in output). To simplify our analysis, we conduct experiments with the weights of $\lambda_{1}=1, \lambda_{q}=0.05$ and $\lambda_{y}=0.5$ in the loss function. The assignment of a lower weight on house prices than on credit is consistent with the empirical evidence that fluctuations in credit are more important

\footnotetext{
${ }^{15}$ Other studies using a similar approach are Agénor et al. (2018), Rubio and Yao (2017), Glocker and Towbin (2012).
} 
than asset prices in predicting financial distress (Agénor and Pereira da Silva; 2017, Agénor et al.; 2018). The assigned weight on output is also smaller than that on credit, reflecting the fact that the primary objective of macro-prudential policy is financial stability. We then derive the optimal policy parameters $\left(\chi_{l, j}^{*}, \chi_{y, j}^{*}\right)$, for all $j=\left\{m_{b}, m_{e}\right\}$, in Eqs. (41) and (42) that minimise Eq. (46) subject to the constraints given by the model.

Table 3 shows the optimal simple rules for both the generic and the sector-specific CcLTV regimes, the corresponding loss function values and the standard deviations of the key policy variables (credit, house prices and output). To provide more insights, we report the results for the three shocks: technology (column 2), financial (household loan loss) (column 3) and housing demand (column 4). ${ }^{16}$

The results indicate that the optimal sector-specific CcLTV regime is more effective than the optimal generic CcLTV regime in minimising the welfare loss. This is particularly so when the economy faces technology and financial shocks - the loss function values under the sector-specific regime (5.2991 for the technology shock and 1.2398 for the financial shock) are smaller than those under the generic regime (5.5218 for the technology shock and 1.5406 for the financial shock). When the housing demand shock hits the economy, the generic regime outperforms the sector-specific regime in terms of minimising welfare loss.

The corresponding optimal parameters (the $\chi_{s}$ ) are shock dependent for both the generic and the sector-specific regimes. As the table shows, both the household and corporate CcLTV regimes require an aggressive reaction to credit following a financial or a housing demand shock, whereas they require only a moderate reaction to credit following a technology shock. The optimal reaction to output is also moderate under technology and housing demand shocks but slightly stronger under a financial shock. Under the sector-specific regime, the corporate CcLTV requires a stronger response to credit and output than the household CcLTV. That is, $\chi_{l, m e}>\chi_{l, m b}$ and $\chi_{y, m e}>\chi_{y, m b}$, except when the economy faces a housing demand shock, in which case the household CcLTV requires a stronger reaction to credit than the corporate $\operatorname{LTV}\left(\chi_{l, m b}>\chi_{l, m e}\right)$.

Table 3 also shows the standard deviations of the three key policy variables (credit, house prices and output) obtained from the optimal CcLTV regimes compared with the baseline regime in which there is no CcLTV (constant LTV ratios). The results show that both the generic and sector-specific CcLTV regimes are effective in minimising the volatility of the three key policy variables, especially for credit. Compared to the generic regime, the sector-specific regime provides a higher degree of macroeconomic stability. This stabilisation effect becomes more significant when the economy faces financial and housing demand shocks.

As a caveat, in interpreting these results it is important to note that the findings in this section only serve to illustrate the effectiveness of the two CcLTV policy regimes. We are not, in any way, suggesting that the authority should be as aggressive as the results suggest. In fact, Schmitt-Grohé and Uribe (2007)

\footnotetext{
${ }^{16}$ To save space, Table 3 shows only the household loan loss shock. The results for the entrepreneur loan loss shock are qualitatively similar to those for the household loan loss shock. For the optimal policy analysis we use the optimal simple rule (osr) unconstrained optimisation routine in Dynare. A smaller loss function value in the same column implies a more effective policy regime.
} 
note that large values of the optimal policy coefficients are difficult to communicate to policymakers or the public. Rubio and Unsal (2017) note that it is not surprising to obtain large values for the optimal policy parameters, especially when the values of the parameters are not constrained within reasonable ranges in the optimisation exercise, as is the case in this paper. ${ }^{17}$ In some cases, the welfare loss (the value of the loss function) can continuously improve even at large values of the policy parameters, but at a very slow rate (Rubio and Unsal; 2017). That is, the optimisation exercise can have diminishing marginal stabilisation effects on the welfare loss, to the point where the additional stabilisation effect is negligible and the welfare loss flattens out as the policy parameters increase further. ${ }^{18}$

Table 3: Optimal rules: generic versus sector-specific.

\begin{tabular}{|c|c|c|c|}
\hline Parameter & Technology shock & Financial shock & Housing demand shock \\
\hline \multicolumn{4}{|c|}{ Optimal generic CcLTV rule } \\
\hline$\chi_{l, m}$ & 1.8534 & 22.5042 & 38.6552 \\
\hline$\chi_{y, m}$ & 0.9461 & 3.5905 & 0.7570 \\
\hline Loss function value $\left(\times 10^{-4}\right)$ & 5.5218 & 1.5406 & 0.4184 \\
\hline \multicolumn{4}{|l|}{ Std. dev. relative to baseline ${ }^{+}$} \\
\hline$L_{t}$ & 0.0617 & 0.0073 & 0.0115 \\
\hline$q_{t}$ & 0.7836 & 0.6954 & 0.8811 \\
\hline$Y_{t}$ & 0.9821 & 0.9268 & 0.8000 \\
\hline \multicolumn{4}{|c|}{ Optimal sector-specific CcLTV rule } \\
\hline$\chi_{l, m_{b}}$ & 1.4663 & 12.7687 & 50.1661 \\
\hline$\chi_{y, m_{b}}$ & 0.5968 & 2.4979 & 0.5730 \\
\hline$\chi_{l, m_{e}}$ & 1.9586 & 34.0370 & 20.3158 \\
\hline$\chi_{y, m_{e}}$ & 1.1799 & 5.3523 & 0.9479 \\
\hline Loss function value $\left(\times 10^{-4}\right)$ & 5.2991 & 1.2398 & 0.4412 \\
\hline \multicolumn{4}{|l|}{ Std. dev. relative to baseline ${ }^{+}$} \\
\hline$L_{t}$ & 0.0606 & 0.0083 & 0.0115 \\
\hline$q_{t}$ & 0.7665 & 0.6260 & 0.9055 \\
\hline$Y_{t}$ & 0.9643 & 0.7805 & 0.6000 \\
\hline
\end{tabular}

+ This value is calculated as the standard deviation (Std. dev.) of a variable $i, i=\{L, q, Y\}$, under the generic or sector-specific CcLTV regime divided by that under the baseline model where there is no CcLTV (i.e. the LTV ratios are constant). A value less than 1 means that a particular policy rule reduces the volatility of variable $i$ relative to the baseline regime.

\section{Impulse response analysis}

In this section, to investigate the effectiveness of the two CcLTV regimes and the transmission mechanisms through which they achieve the two objectives of the macro-prudential policy, we present the impulse responses of the main variables (shown in Fig. 2 to Fig. 4) following technology, financial and

\footnotetext{
${ }^{17} \mathrm{We}$ do not restrict the values of the parameters in the optimisation exercise because the literature has yet to reach consensus on the reasonable ranges or bands for the parameters in macro-prudential policy rules.

${ }^{18}$ In monetary policy studies, Schmitt-Grohé and Uribe (2007) also find that unconstrained optimal policy rules call for a much larger inflation coefficient (about 332) but yield a negligible welfare improvement.
} 
housing demand shocks. We contrast the baseline regime, defined by constant LTV ratios in Eqs. (10) and (19), with the optimal generic and sector-specific CcLTV regimes. ${ }^{19}$ This allows us to investigate whether the sector-specific regime is more effective than the generic one in achieving financial and macroeconomic stability, where there are two types of borrowers from distinct sectors of the credit market. The analysis with the three shocks also enables us to establish whether the effectiveness of the CcLTV depends on the type of shock.

\subsection{Technology shock}

Fig. 2 shows the impulse responses of the main variables to a positive technology shock under the baseline regime and the generic and sector-specific CcLTV regimes. The shock generates expansionary effects in the economy. Under the baseline regime (the black solid line), it increases the marginal productivity of housing, which in turn increases entrepreneurs' demand for housing and hence house prices. Through the borrowing constraint channel, the rise in house prices stimulates credit growth as the value of the collateral asset increases, and results in an increase in output and consumption. The bank also increases its lending rates, in response to the higher demand for credit.

Turning to the generic (the red dash-dot line) and sector-specific (the blue asterisk line) CcLTV regimes, we find that both regimes imply that the increase in credit and output triggers the household and corporate LTV ratios to decline temporarily. This tightens households' and entrepreneurs' borrowing constraints and reduces the extent of an increase in borrowers' demand for credit and investment in housing. House prices increase less than they did under the baseline regime. In addition to this indirect effect, the CcLTV also has a direct effect on house prices through the borrowers' optimal conditions for housing (Eqs. (12) and (20)): the fall in the LTV ratios leads directly to a decline in house prices. This further tightens collateral constraints and mitigates the amplification effects of the financial accelerator mechanism (Bernanke et al.; 1999).

Both CcLTV regimes are effective in attenuating the impact of the technology shock on financial variables, including house prices, but have limited effects on the real variables (consumption and output). The CcLTV limits the extent to which the borrowers can take on leverage and hence the demand for credit. With the lower demand for credit, lending rates do not need to respond as aggressively as in the baseline regime. The moderate increase in demand for credit, in turn, reduces the borrowers' debt burden, and enables them to consume more under the two CcLTV regimes than under the baseline regime. On the other hand, the moderate increase in credit and deposits, coupled with the fall in interest rates, reduces the bank's and the patient households' interest income. As a result, the bank and the patient households consume less under the CcLTV regimes than under the baseline regime. Therefore, the borrowers' higher consumption compensates for the lower consumption by patient households and the bank, such that the overall impact of the CcLTV on aggregate consumption and hence output becomes limited. These findings are also consistent with the literature (see, e.g., Rubio and Carrasco-Gallego (2014) and Ravn (2016)).

\footnotetext{
${ }^{19}$ The macro-prudential policy parameter values are taken from Table 3 in the optimal rule analysis.
} 

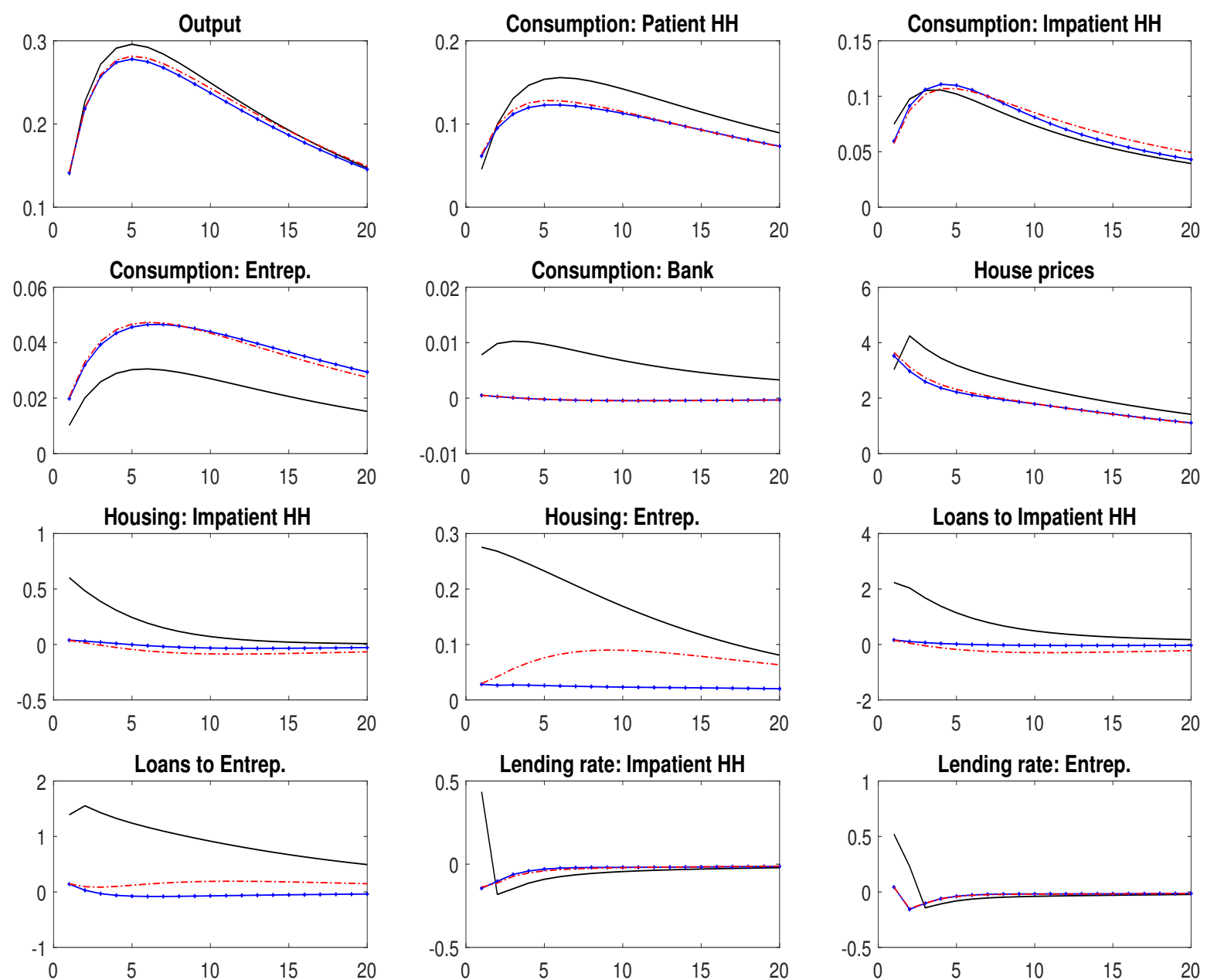

Baseline —-Sector specific CcLTV -.-... Generic CcLTV

Figure 2: Impulse responses to a positive technology shock under the baseline, generic and sector-specific CcLTV regimes. $\mathrm{HH}$ and Entrep denote household and entrepreneur, respectively. Variables are expressed in \% deviations from the steady state, and interest rates are in annualised percentage points. Ordinate: time horizon in quarters.

A comparison of the two CcLTV regimes suggests that their effectiveness is more or less the same following the technology shock. However, the sector-specific regime marginally outperforms the generic regime in dampening fluctuations in house prices, aggregate consumption and output. In the credit and housing markets, Fig. 2 shows that the sector-specific CcLTV regime is slightly more effective than the generic regime in dampening fluctuations in entrepreneurs' credit and housing stock while the generic regime outperforms the sector-specific regime in dampening fluctuations in households' credit and housing stock. This is because the optimal implementation of the corporate CcLTV requires a stronger policy response to credit under the sector-specific regime than under the generic regime. However, the optimal household CcLTV requires stronger policy response to credit under the generic regime than under the sector-specific regime. 


\subsection{Financial (household loan loss) shock}

Fig. 3 compares the attenuation effects of the generic and sector-specific regimes following a negative financial shock (modelled as an exogenous increase in bank loan losses on household loans). ${ }^{20}$ The negative financial shock causes a recession in the real economy through the spillover from the financial sector. Under the baseline regime, the shock impairs the bank's balance sheets and reduces its net worth. Through the bank's capital constraint channel, this decreases the credit supply to both impatient households and entrepreneurs. Consequently, the demand for housing declines, dragging house prices down. This in turn results in a further decline in credit through the borrowing constraint channel. In an attempt to boost profits and rebuild net worth, the bank increases its lending rates. This further depresses the demand for credit, reduces aggregate consumption and results in a protracted recession.
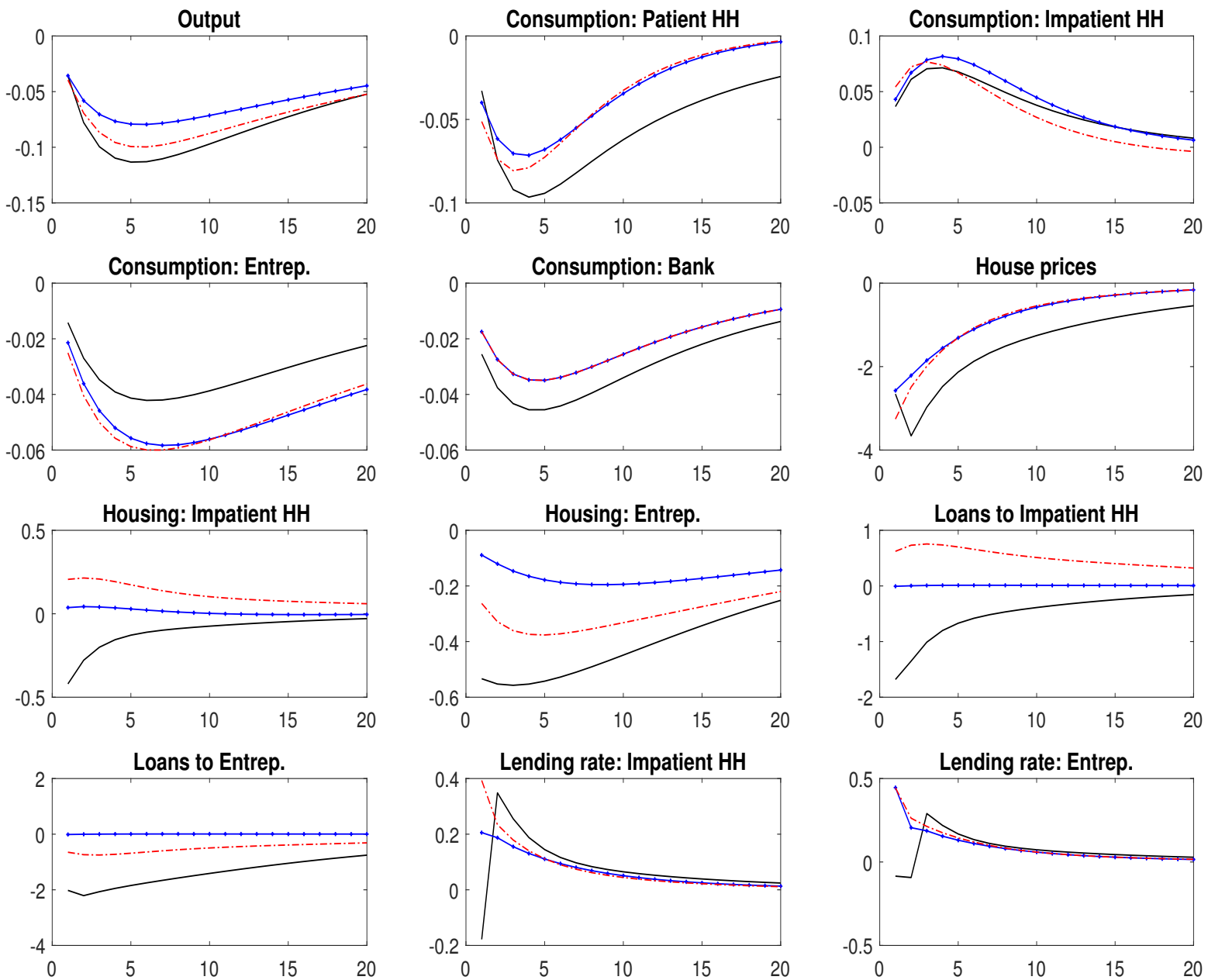

Baseline $\longrightarrow$ Sector specific CcLTV -.-... Generic CcLTV

Figure 3: Impulse responses to a negative financial shock (household loan loss shock only) under the baseline, generic and sector-specific CcLTV regimes. HH and Entrep denote household and entrepreneur, respectively. Variables are expressed in $\%$ deviations from the steady state, and interest rates are in annualised percentage points. Ordinate: time horizon in quarters.

\footnotetext{
${ }^{20}$ Here we only report the results of the household loan loss shock. The results are similar for the entrepreneurs' loan loss shock except that the entrepreneurs' consumption increases while that of the borrower households declines.
} 
The presence of CcLTV mitigates the recessionary effect of the financial shock. Under both the generic and sector-specific regimes, the fall in credit and output activates the CcLTV. The LTV ratios increase temporarily, leading to an increase in the value of collateral assets (housing). This enables borrowers to borrow more out of their housing wealth and therefore mitigates the decline in demand for credit. As a result, the fall in borrowers' demand for housing, and hence the fall in house prices, becomes smaller under the CcLTV than under the baseline regime. This, in turn, dampens the amplification effects of the borrowing constraint channel. Consequently, the extent of the increase in lending rates becomes smaller under both CcLTV regimes than under the baseline regime. The recessionary effect of the shock becomes less pronounced.

The results further show that the CcLTV affects consumption by the different agents (patient and impatient households, entrepreneurs and the bank) asymmetrically. For borrowers, the increase in the LTV ratios mitigates the decline in demand for credit and this effectively increases their debt service burden more than the baseline regime does. As a result, the increase in the impatient households' consumption is reduced while the entrepreneurs' consumption drops further. ${ }^{21}$ Similarly, the attenuation effect of the CcLTV mitigates the fall in the patient households' and the bank's consumption by reducing the fall in their interest income.

Comparing the impact of the two CcLTV regimes, we find that the sector-specific regime is more effective than the generic CcLTV regime in mitigating the fall in the entrepreneurs' credit and hence their demand for housing. On the other hand, the generic CcLTV regime is more effective in mitigating the fall in the impatient households' credit and their demand for housing. This is because the optimal implementation of the household CcLTV requires a stronger policy response to credit under the generic regime than under the sector-specific regime. However, the optimal corporate CcLTV requires a stronger policy response to credit under the sector-specific regime than under the generic regime. Compared to the case of the technology shock, Fig. 3 shows that the sector-specific regime significantly outperforms the generic regime in dampening the fluctuations in aggregate consumption, output and house prices. In this case, the extent of over-reaction in the household credit market sector and under-reaction in the corporate credit market sector under the generic regime is more pronounced. Instead of mitigating the fall in household credit, the generic regime causes it to increase.

It is important to note that when only one sector of the credit market is hit by a negative financial shock (in this case the household loan market), the sector-specific CcLTV regime plays a very important role in stabilising the financial sector. We can see this because when we implement the sector-specific regime rather than the generic regime, the CcLTV regime moderately mitigates the decline of household credit while significantly stabilising corporate credit. Consequently, the negative effect of the shock on entrepreneurs' consumption under the sector-specific regime is less than under the generic regime. At the same time, the sector-specific CcLTV regime has a larger positive impact on impatient households' consumption. This, in turn, contributes significantly to macroeconomic stability - output recovers

\footnotetext{
${ }^{21}$ For household borrowers, the shock increases their income indirectly. By paying less than the contractual amount of the loan, household borrowers are able to spend more than previously anticipated. The results in Fig. 3 are based on household loan loss shock only. This shock does not have an indirect income effect on entrepreneurs' consumption.
} 
significantly under the sector-specific regime.

\subsection{Housing demand shock}

Fig. 4 shows the impulse responses of the main variables following a positive housing demand shock. As with the case of a positive technology shock, the shock generates expansionary effects in the economy, leading to an increase in the demand for housing and in house prices. Through the collateral constraint channel, the increase in house prices allows borrowers to increase their borrowing and stimulates aggregate consumption and output. ${ }^{22}$ In response to the higher demand for credit, the bank also increases its lending rates.
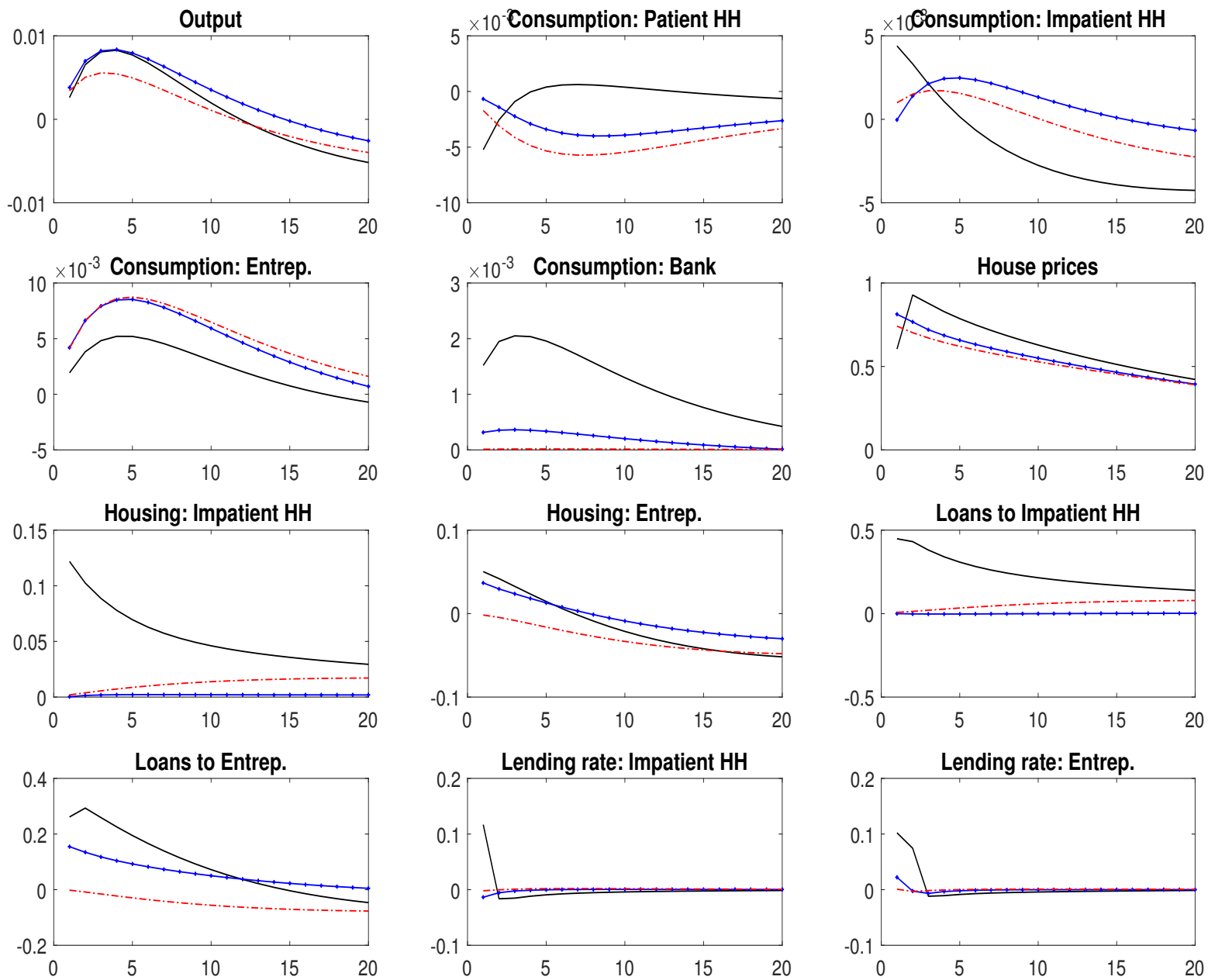

Baseline —-Sector specific CcLTV -..... Generic CcLTV

Figure 4: Impulse responses to a positive housing demand shock under the baseline, generic and sector-specific CcLTV regimes. HH and Entrep denote household and entrepreneur, respectively. Variables are expressed in \% deviations from the steady state, interest rates in annualised percentage points. Ordinate: time horizon in quarters.

Under the two CcLTV regimes, the regulatory authority decreases the LTV ratios in response to the increase in credit and output, and this reduces the increase in house prices and the demand for credit

${ }^{22}$ At disaggregate level, the shock leads to an initial fall in household savers' consumption. This is because the increase in the return to deposits creates an incentive for them to increase savings and forgo consumption. 
through the borrowing constraint channel. Since the CcLTV reduces the increase in borrowing and lending rates, the borrowers' debt service costs decline. This, in turn, allows borrowers to consume more than they did under the baseline regime. Similarly, the interest income accruing to both the bank and the patient households falls and this causes a fall in the patient households' consumption and reduces the increase in the bank's consumption.

Unlike the effect we saw in the case of a negative financial shock, the generic regime is more effective than the sector-specific regime in reducing fluctuations in output and house prices. Indeed, except for the impatient households' credit and housing, the generic regime outperforms the sector-specific regime in achieving financial and macroeconomic stability. ${ }^{23}$ This implies that when both sectors of the credit market are hit by the same shock, the generic regime is more effective than the sector-specific regime. In the case of a housing demand shock, since the CcLTV works through the borrowing constraint channel and housing is used as a collateral asset for both types of borrowers, the shock affects both types of borrowers in the same way. The regulatory authority can, therefore, implement the generic CcLTV regime accordingly. In this way, the authority can achieve its macro-prudential policy objectives of financial and macroeconomic stability.

\section{$7 \quad$ Efficiency policy frontier}

In this section, we present the outcome of the generic and the sector-specific regimes in the form of a two-dimensional efficiency policy frontier on credit and output. The efficiency policy frontier shows the locus of the volatility of credit and output calculated at each set of optimal policy coefficients that are obtained for different combinations of loss function weights. To perform the exercise, we simplify the loss function (46) by setting the weight on the volatility of house prices to zero, $\lambda_{q}=0$, and allow the weights on credit and output to vary inversely within the range $\lambda \in[0,1]$. That is:

$$
\mathcal{L}_{m p}=\lambda \sigma_{l}^{2}+(1-\lambda) \sigma_{y}^{2}
$$

For each combination of the loss function weights, we compute the set of optimal policy coefficients that yields the lowest welfare loss and then plot the corresponding volatility of credit and output in a twodimensional plot, as shown in Fig. 5. ${ }^{24}$ Moving from left to right in Fig. 5, the weight on the volatility of credit $(\lambda)$ increases from 0 to 1 while that on volatility of output decreases from 1 to 0 .

The efficiency policy frontiers under the two alternative policy regimes present a clear trade-off between financial and macroeconomic stability, as the authority adjusts its preference between the two policy objectives. The maximum attainable reduction in output volatility can be achieved at the expense of increasing credit volatility. Compared with the baseline regime (the small black square), the two alternative CcLTV regimes can virtually eliminate credit volatility without increasing output volatility. This means that, compared to the baseline case, the two policy regimes can achieve the maximum attainable financial stability benefits without compromising macroeconomic stability.

\footnotetext{
${ }^{23}$ This is because the optimal household CcLTV rule requires a stronger response to credit under the sector-specific regime than under the generic regime.

${ }^{24}$ The analysis is conducted for financial shock. We perform a similar exercise for the other two shocks (technology and housing demand) and obtain similar results. These results are reported in Appendix C.
} 


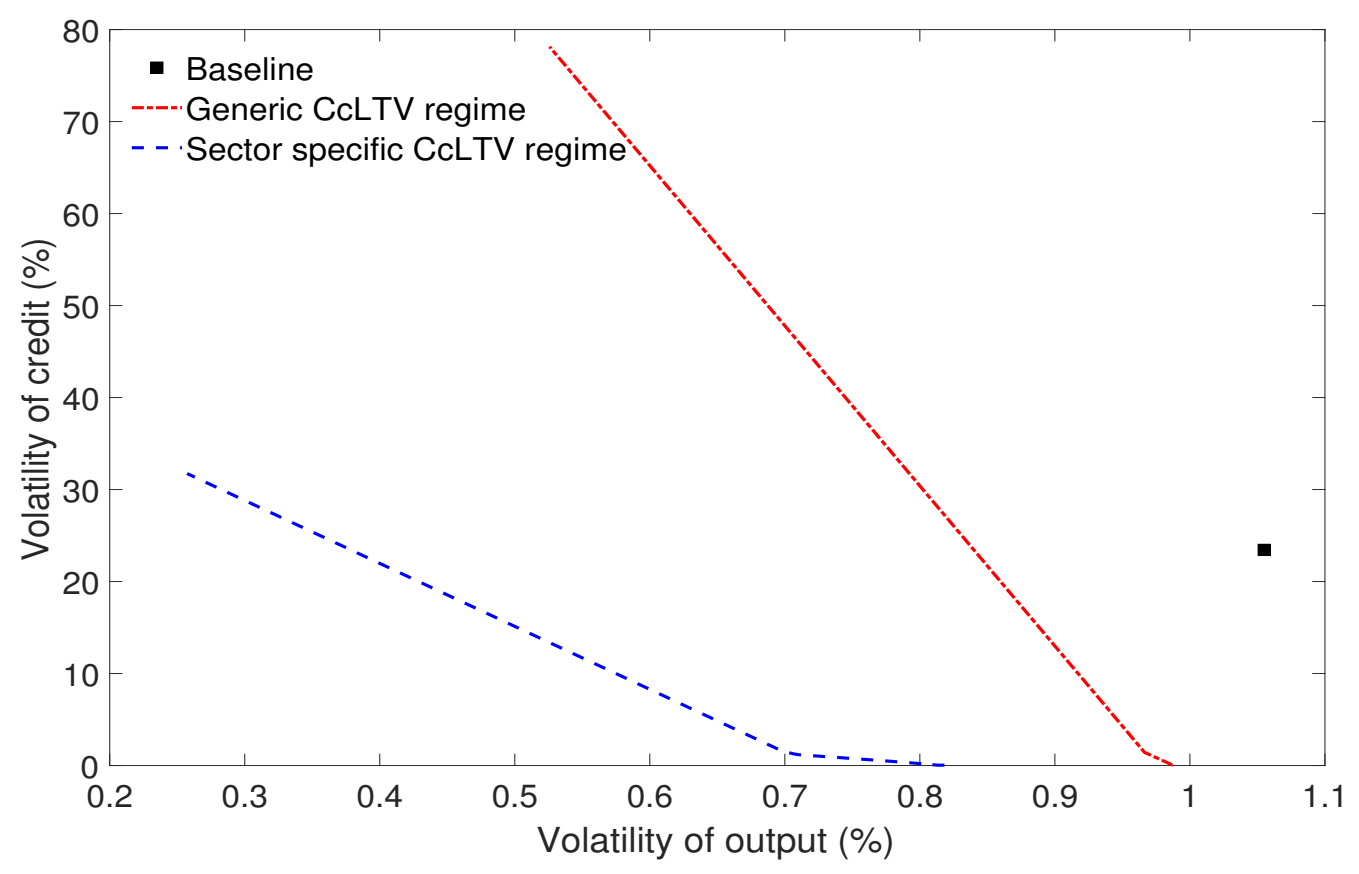

Figure 5: The efficiency policy frontier $(\lambda \in[0,1])$.

A comparison between the two CcLTV regimes suggests that the sector-specific CcLTV regime is more effective than the generic CcLTV regime in stabilising both credit and output volatility. Furthermore, the sector-specific regime can deliver a larger reduction in output volatility at a lower cost of financial instability. This can be seen in the flatter frontier. In summary, the results suggest that the appropriate implementation of CcLTV has the potential to deliver both financial and macroeconomic stability. This concurs with the findings in Brzoza-Brzezina et al. (2015), Rubio and Yao (2017), in which the authors establish that the CcLTV reduces the volatility of both credit and output. The sector-specific regime delivers a more stable economic system than the generic regime.

\section{Implementing the CcLTV regulation: generic versus sector-specific rules}

To understand better how the proposed CcLTV regimes work, we simulate the model with different values of parameters in the policy rules Eqs. (41) and (42) and trace the impact on the volatility of credit, house prices and output. This exercise demonstrates the possible trade-off between financial stability and macroeconomic stability when the regulatory authority responds more aggressively to changes in credit and output. To perform this exercise, we allow the two policy parameters to vary and plot the variance surfaces of credit, house prices and output against these two parameters. ${ }^{25}$

Fig. 6 shows the results for the generic CcLTV regime. The first two panels show that this regime is effective in delivering financial stability. A more aggressive response to aggregate credit (movement along $\chi_{l m}-$ axis) leads to a substantial fall in the volatility of aggregate credit and house prices.

\footnotetext{
${ }^{25}$ We simulate the model with all the shocks and perform the grid search over the ranges $\chi_{l, m}=[0,5]$ and $\chi_{y, m}=[0,2]$ with the grid step of 0.1 and 0.04 for $\chi_{l, m}$ and $\chi_{y, m}$, respectively, as these are sufficient for the purpose of this paper. In a separate exercise, we also experiment with the values of $\chi_{l, m}>5$ and $\chi_{y, m}>2$. The same conclusion emerges.
} 
Nonetheless, this stabilisation benefit diminishes as the policy becomes more aggressive. The mesh plots further show that a more aggressive response to changes in output (movement along $\chi_{y m}$ - axis) can only enhance financial stability with a moderate response to changes in credit (with $\chi_{l m}<2$ ). The third panel of Fig. 6 shows that the generic CcLTV regime has a potential to deliver macroeconomic stability if authority adjusts the LTV ratios to changes in output more aggressively $\left(\chi_{y, m} \Longrightarrow 2\right)$, but only marginally to changes in credit $\left(\chi_{l, m} \Longrightarrow 0\right)$.
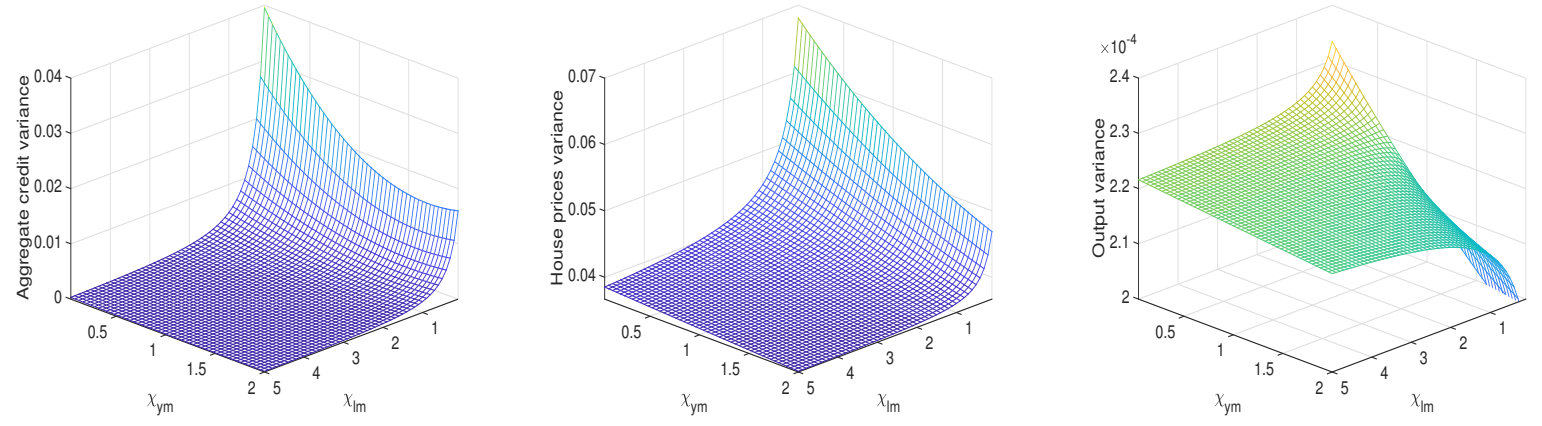

Figure 6: Policy response impact (different values of $\chi_{l m}$ and $\chi_{y m}$ ): generic CcLTV regime.

Figs. 7 and 8 show the results for the sector-specific CcLTV. In this case, we perform the same exercise with household and corporate CcLTV independently. That is, we perform the simulation exercise with the household (corporate) CcLTV while holding the corporate (household) LTV ratio constant. Fig. 7 shows the results for the household CcLTV rule and Fig. 8 shows the volatility of corporate credit, as opposed to the aggregate credit.
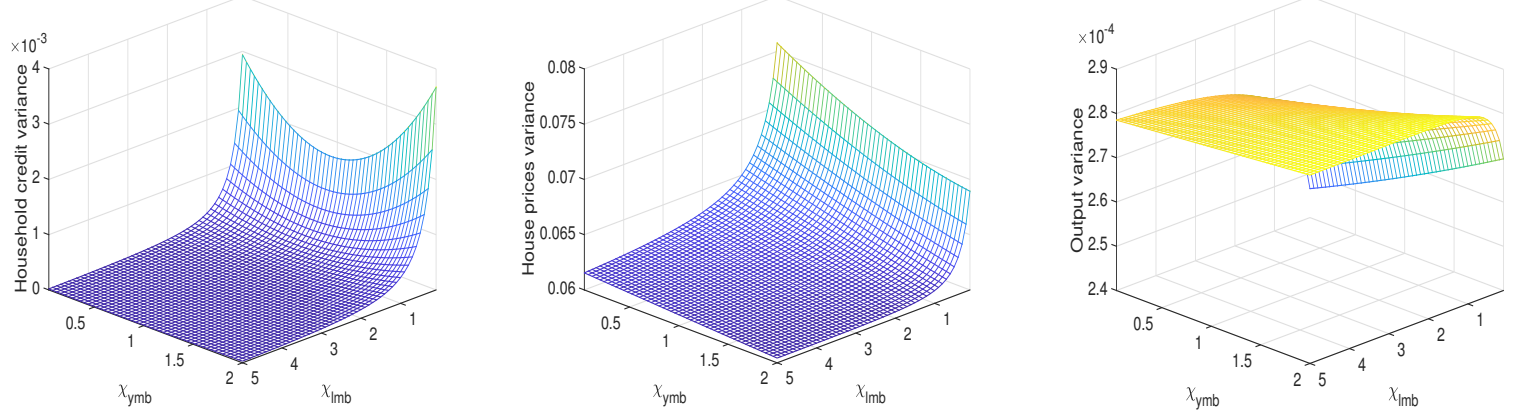

Figure 7: Policy response impact (different values of $\chi_{l m b}$ and $\chi_{y m b}$, given $\chi_{l m e}=\chi_{y m e}=0$ ): sector-specific CcLTV regime.

The results are similar to those for the generic CcLTV regime. However, the effect of the response to changes in output on sector-specific credit differs for household credit and corporate credit. With a moderate response to sector-specific credit, the stabilisation effect of the response to changes in output on corporate credit increases monotonically as it becomes more aggressive. For household credit, however, this effect increases only up to $\chi_{y m b}=1.5$, and thereafter it becomes weaker - the volatility of household credit starts increasing. Another difference is that the corporate CcLTV enhances macroeconomic sta- 

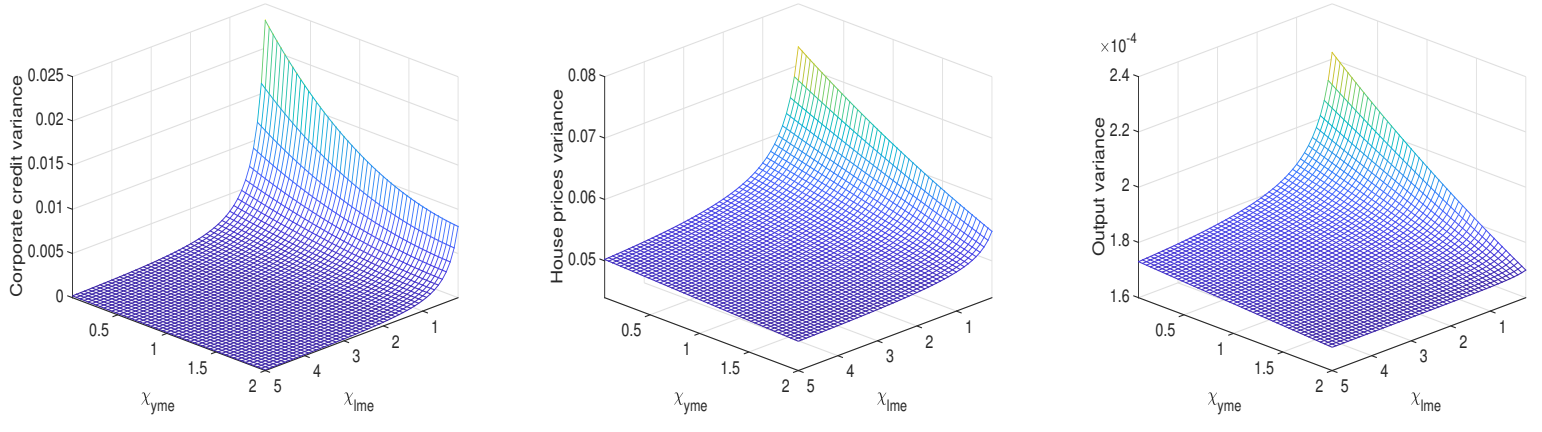

Figure 8: Policy response impact (different values of $\chi_{l m e}$ and $\chi_{y m e}$, given $\chi_{l m b}=\chi_{y m b}=0$ ): sector-specific CcLTV regime.

bility when the regulation becomes more aggressive to changes in corporate credit and output, whereas an aggressive household CcLTV does not improve macroeconomic stability.

The general conclusion to be drawn from this exercise is that the proposed CcLTV regimes have the potential to deliver on financial and macroeconomic stability mandates. However, this stabilisation effect on financial stability diminishes if the regulator responds aggressively to changes in credit. Responses to changes in output can achieve financial stability only if the regulator responds to changes in financial variables moderately. However, regardless of whether the regulatory authority responds to changes in output aggressively or not, an aggressive response to changes in credit does not contribute to macroeconomic stability, whereas a moderate response to changes in credit has a significant impact.

\section{Conclusion}

This paper considers the optimal design and the implications of the CcLTV regulation in a model economy where there are two types of borrowers from distinct sectors of the credit market. We look at two policy regimes, generic and sector-specific, and compare their effectiveness in enhancing financial and macroeconomic stability. We find that both regimes are effective, especially when the economy is hit by financial and housing demand shocks. This is achieved mainly by reducing the amplification effects of the borrowing constraint channel. The effectiveness of both regimes is, however, shock dependent. When the economy faces a technology shock, their effectiveness is more or less the same. When the economy faces a financial shock, the sector-specific regime significantly outperforms the generic regime in reducing business cycle fluctuations, whereas the opposite is true when the economy is hit by a housing demand shock. The efficiency policy frontiers under the two alternative policy regimes present a clear trade-off between financial and macroeconomic stability, as the authority adjusts its preference between the two policy objectives. The sector-specific CcLTV regime is more effective than the generic CcLTV regime in reducing the volatility of credit and output.

Our findings highlight the importance of identifying the origin of the shock in order to implement the CcLTV regulation appropriately. More importantly, our findings suggest that, in order to enhance the effectiveness of the macro-prudential policy, the regulator should consider borrowers' heterogeneity 
and tailor the CcLTV regulation according to the specific conditions of each sector of the credit market, rather than to the aggregate credit market condition. In this way, the regulator can directly target the credit market sector, or the borrower type, where systemic risk is developing. To further enhance our understanding of macro-prudential policies, the analysis in this paper can be developed in several directions. One possible avenue is to introduce nominal rigidities into the model and study the role of monetary policy and the extent to which it can complement the sector-specific CcLTV regulation in fostering financial and macroeconomic stability. Another possibility is to extend the analysis to a small open economy model and study the role of the CcLTV regulation in mitigating the impact of foreign shocks. 


\section{References}

Agénor, P.-R., Alper, K., da Silva, L. P., 2018. External shocks, financial volatility and reserve requirements in an open economy. Journal of Financial Stability 83, 23-43.

Agénor, P.-R., Pereira da Silva, L., 2017. Cyclically adjusted provisions and financial stability. Journal of International Money and Finance 28, 143-162.

Angelini, P., Neri, S., Panetta, F., 2014. The interaction between capital requirements and monetary policy. Journal of Money, Credit and Banking 46 (6), 1073-1112.

Bernanke, B., Gertler, M., Gilchrist, S., 1999. The financial accelerator in a quantitative business cycle framework. In: Taylor, J. B., Woodford, M. (Eds.), Handbook of Macroeconomics. Vol. 1c. NorthHolland, Amsterdam, pp. 1341-1393.

Brzoza-Brzezina, M., Kolasa, M., Makarski, K., 2015. Macroprudential policy and imbalances in the euro area. Journal of International Money and Finance 51, 137-154.

Chaney, T., Sraer, D., Thesmar, D., 2012. The collateral channel: how real estate shocks affect corporate investment. American Economic Review 102 (6), 2381-2409.

Claessens, S., Ghosh, S. R., Mihet, R., 2013. Macro-prudential policies to mitigate financial system vulnerabilities. Journal of International Money and Finance 39, 153-185.

Garbers, C., Liu, G., 2018. Macroprudential policy and foreign interest rate shocks: a comparison of loan-to-value and capital requirements. International Review of Economics \& Finance 58, 683-698.

Glocker, C., Towbin, P., 2012. Reserve requirements for price and financial stability: when are they effective? International Journal of Central Banking 8 (1), 65-113.

Guerrieri, L., Iacoviello, M., 2017. Collateral constraints and macroeconomic asymmetries. Journal of Monetary Economics 90 (C), 28-47.

Gupta, R., Sun, X., 2016. Housing market spillovers in South Africa: evidence from an Estimated Small Open Economy DSGE Model. Working paper No. 2016-41, University of Pretoria, Department of Economics.

Iacoviello, M., 2005. House prices, borrowing constraints, and monetary policy in the business cycle. American Economic Review 95 (3), 739-764.

Iacoviello, M., 2015. Financial business cycles. Review of Economic Dynamics 18 (1), 140-163.

Iacoviello, M., Minetti, R., 2006. International business cycles with domestic and foreign lenders. Journal of Monetary Economics 53 (8), 2267-2282.

IMF, 2011. Durable financial stability: getting there from here. Global Financial Stability Report April 2011, International Monetary Fund. 
Lambertini, L., Mendicino, C., Punzi, M. T., 2013. Leaning against boom-bust cycles in credit and housing prices. Journal of Economic Dynamics and Control 37 (8), 1500-1522.

Liu, G., Gupta, R., 2007. A small-scale DSGE model for forecasting the South African economy. South African Journal of Economics 75 (2), 179-193.

Liu, G., Seeiso, N. E., 2012. Basel II procyclicality: the case of South Africa. Economic Modelling 29 (3), 848-857.

Liu, Z., Wang, P., Zha, T., 2013. Land-price dynamics and macroeconomic fluctuations. Econometrica 81 (3), 1147-1184.

Mendicino, C., Punzi, M. T., 2014. House prices, capital inflows and macroprudential policy. Journal of Banking \& Finance 49, 337-355.

Minetti, R., Peng, T., 2013. Lending constraints, real estate prices and business cycles in emerging economies. Journal of Economic Dynamics and Control 12 (37), 2397-2416.

Punzi, M. T., Rabitsch, K., 2018. Effectiveness of macroprudential policies under borrower heterogeneity. Journal of International Money and Finance 85, 251-261.

Quint, D., Rabanal, P., 2014. Monetary and macroprudential policy in an estimated DSGE model of the Euro Area. International Journal of Central Banking 10 (2), 169-236.

Ravn, S. H., 2016. Endogenous credit standards and aggregate fluctuations. Journal of Economic Dynamics and Control 69, 89-111.

Rubio, M., Carrasco-Gallego, J. A., 2014. Macroprudential and monetary policies: implications for financial stability and welfare. Journal of Banking \& Finance 49, 326-336.

Rubio, M., Unsal, F., 2017. Macroprudential policy, incomplete information and inequality: the case of low-income and developing countries. IMF Working Papers No 17/59.

Rubio, M., Yao, F., 2017. Macroprudential policies in a low interest-rate environment. Discussion Paper Series 2017/04, Reserve Bank of New Zealand.

Schmitt-Grohé, S., Uribe, M., 2007. Optimal simple and implementable monetary and fiscal rules. Journal of Monetary Economics 54 (6), 1702-1725. 


\section{A Complete set of equations for the model}

\section{Patient households (Savers)}

$$
\begin{gathered}
C_{s, t}+D_{t}+q_{t}\left(H_{s, t}-H_{s, t-1}\right)=W_{s, t} N_{s, t}+R_{d, t-1} D_{t-1}, \\
1=\beta_{s} E_{t} \frac{U_{C s, t+1}}{U_{C s, t}} R_{d, t}, \\
q_{t}=j \frac{A_{t}}{H_{s, t} U_{C s, t}}+\beta_{s} E_{t}\left(\frac{U_{C s, t+1}}{U_{C s, t}}\right) q_{t+1}, \\
W_{s, t}=\frac{\tau}{\left(1-N_{s, t}\right) U_{C s, t}},
\end{gathered}
$$

where $U_{C s, t}=\frac{1-\eta_{s}}{C_{s, t}-\eta_{s} C_{s, t-1}}$.

\section{Impatient households (Borrowers)}

$$
\begin{gathered}
C_{b, t}+R_{b, t-1} L_{b, t-1}+q_{t}\left(H_{b, t}-H_{b, t-1}\right)=W_{b, t} N_{b, t}+L_{b, t}+\zeta_{b, t}, \\
L_{b, t}=m_{b, t} E_{t}\left[\frac{q_{t+1}}{R_{b, t}} H_{b, t}\right], \\
1=\beta_{b} E_{t} \frac{U_{C b, t+1}}{U_{C b, t}} R_{b, t}+\frac{\lambda_{b, t}}{U_{C b, t}}, \\
q_{t}=j \frac{A_{t}}{H_{b, t} U_{C b, t}}+\beta_{b}\left(1-m_{b, t}\right) E_{t}\left(\frac{U_{C b, t+1}}{U_{C b, t}}\right) q_{t+1}+m_{b, t} E_{t} \frac{q_{t+1}}{R_{b, t}}, \\
W_{b, t}=\frac{\tau}{\left(1-N_{b, t}\right) U_{C b, t}},
\end{gathered}
$$

where $U_{C b, t}=\left(1-\eta_{b}\right) /\left(C_{b, t}-\eta_{b} C_{b, t-1}\right)$.

\section{Entrepreneurs}

$$
\begin{gathered}
C_{e, t}+q_{t}\left(H_{e, t}-H_{e, t-1}\right)+R_{e, t} L_{e, t-1}+W_{s, t} N_{s, t}+W_{b, t} N_{b, t}=Y_{t}+L_{e, t}+\zeta_{e, t}, \\
Y_{t}=Z_{t} H_{e, t-1}^{\nu}\left[N_{s, t}^{1-\sigma} N_{b, t}^{\sigma}\right]^{1-\nu}, \\
L_{e, t}=m_{e, t} E_{t}\left(\frac{q_{t+1}}{R_{e, t+1}} H_{e, t}\right), \\
q_{t}=\beta_{e} E_{t} \frac{U_{C e, t+1}}{U_{C e, t}}\left(\nu \frac{Y_{t+1}}{H_{e, t}}+\left(1-m_{e, t}\right) q_{t+1}\right)+m_{e, t} E_{t} \frac{q_{t+1}}{R_{e, t+1}}, \\
W_{s, t} N_{s, t}=(1-\sigma)(1-\nu) Y_{t}, \\
W_{b, t} N_{b, t}=\sigma(1-\nu) Y_{t},
\end{gathered}
$$

where $U_{C e, t}=\left(1-\eta_{e}\right) /\left(C_{e, t}-\eta_{e} C_{e, t-1}\right)$. 


\section{The bank}

$$
\begin{gathered}
C_{f, t}+R_{d, t-1} D_{t-1}+L_{b, t}+L_{e, t}+A C_{b f, t}+A C_{e f, t}=D_{t}+R_{b, t-1} L_{b, t-1}+R_{e, t} L_{e, t-1}-\zeta_{t}, \\
D_{t}=\left(1-w_{e} \kappa\right)\left(L_{e, t}-E_{t} \zeta_{e, t+1}\right)+\left(1-w_{b} \kappa\right)\left(L_{b, t}-E_{t} \zeta_{b, t+1}\right), \\
\beta_{f} E_{t} \frac{U_{C f, t+1}}{U_{C f, t}} R_{d, t}=\left(1-\lambda_{f, t} / U_{C f, t}\right), \\
\beta_{f} E_{t} \frac{U_{C f, t+1}}{U_{C f, t}} R_{b, t}=1-\left(1-w_{b} \kappa\right)\left(\lambda_{f, t} / U_{C f, t}\right)+\frac{\phi_{b f}}{L_{b}}\left(L_{b, t}-L_{b, t-1}\right) . \\
\beta_{f} E_{t} \frac{U_{C f, t+1}}{U_{C f, t}} R_{e, t+1}=1-\left(1-w_{e} \kappa\right)\left(\lambda_{f, t} / U_{C f, t}\right)+\frac{\phi_{e f}}{L_{e}}\left(L_{e, t}-L_{e, t-1}\right),
\end{gathered}
$$

where $U_{C f, t}=\left(1-\eta_{f}\right) /\left(C_{f, t}-\eta_{f} C_{f, t-1}\right), A C_{b f, t}=\frac{\phi_{b f}}{2} \frac{\left(L_{b, t}-L_{b, t-1}\right)^{2}}{L_{b}}, A C_{e f, t}=\frac{\phi_{e f}}{2} \frac{\left(L_{e, t}-L_{e, t-1}\right)^{2}}{L_{e}}$.

Aggregate consumption and market clearing conditions

$$
\begin{gathered}
C_{t}=C_{s, t}+C_{b, t}+C_{e, t}+C_{f, t} . \\
H_{s, t}+H_{b, t}+H_{e, t}=1 . \\
L_{b, t}+L_{e, t}=L_{t} .
\end{gathered}
$$

Household LTV rule

$$
m_{b, t}=m_{b}\left(\frac{L_{b, t}}{L_{b}}\right)^{-\chi_{l}}\left(\frac{Y_{t}}{Y}\right)^{-\chi_{y}}
$$

Entrepreneur (corporate) LTV rule

$$
m_{e, t}=m_{e}\left(\frac{L_{e, t}}{L_{e}}\right)^{-\chi_{l}}\left(\frac{Y_{t}}{Y}\right)^{-\chi_{y}}
$$

\section{Shock processes}

$$
\begin{aligned}
\log \left(A_{t}\right) & =\rho_{a} \log \left(A_{t-1}\right)+\xi_{a, t}, \\
\zeta_{b, t} & =\rho_{\zeta} \zeta_{b, t-1}+\xi_{\zeta_{b, t}}, \\
\zeta_{e, t} & =\rho_{\zeta} \zeta_{e, t-1}+\xi_{\zeta_{e, t}}, \\
\log \left(Z_{t}\right) & =\rho_{z} \log \left(Z_{t-1}\right)+\xi_{z, t} .
\end{aligned}
$$




\section{B Steady-state of the model}

Interest rates

$$
\begin{gathered}
R_{d}=1 / \beta_{s}, \\
R_{b}=\frac{w_{b} \kappa}{\beta_{f}}+\frac{\left(1-w_{b} \kappa\right)}{\beta_{s}}, \\
R_{e}=\frac{w_{e} \kappa}{\beta_{f}}+\frac{\left(1-w_{e} \kappa\right)}{\beta_{s}} .
\end{gathered}
$$

\section{Some useful constants}

$$
\begin{gathered}
z_{1}=\frac{j}{1-\beta_{s}}, \\
z_{2}=\frac{j}{1-\beta_{b}-m_{b}\left(1 / R_{b}-\beta_{b}\right)}, \\
z_{3}=\frac{1}{1+m_{b}\left(1-1 / R_{b}\right) z_{2}}, \\
z_{4}=\left[1-\beta_{e}-m_{e}\left(1 / R_{e}-\beta_{e}\right)\right] / \beta_{e}, \\
z_{5}=\left(R_{d}-1\right)\left(1-w_{e} \kappa\right) \frac{m_{e}}{R_{e}} \frac{\nu}{z_{4}}, \\
z_{6}=\left(R_{d}-1\right)\left(1-w_{b} \kappa\right) \frac{m_{b}}{R_{b}} z_{2} z_{3}, \\
z_{7}=(1-\sigma)(1-\nu), \\
z_{8}=1+\frac{z_{5}}{z_{7}}+z_{6} \frac{\sigma}{1-\sigma} .
\end{gathered}
$$

\section{Supply of labour}

$$
\begin{aligned}
& N_{s}=1 /\left(1+z_{8} \tau\right), \\
& N_{b}=1 /\left(1+z_{3} \tau\right) .
\end{aligned}
$$

\section{Housing shares}

$$
\begin{aligned}
H_{e} & =\frac{\nu}{\nu+z_{1} z_{4} z_{7} z_{8}+z_{2} z_{3} z_{4} \sigma(1-\nu)}, \\
H_{s} & =\frac{z_{1} z_{4} z_{7} z_{8}}{\nu+z_{1} z_{4} z_{7} z_{8}+z_{2} z_{3} z_{4} \sigma(1-\nu)} .
\end{aligned}
$$

Housing-output ratios

$$
\begin{gathered}
q H_{s} / Y=z_{1} z_{7} z_{8}, \\
q H_{b} / Y=z_{2} z_{3} \sigma(1-\nu), \\
q H_{e} / Y=\frac{\nu}{z_{4}} .
\end{gathered}
$$




\section{Consumption-output ratios}

$$
\begin{gathered}
C_{s} / Y=z_{7} z_{8}, \\
C_{b} / Y=z_{3} \sigma(1-\nu), \\
C_{e} / Y=\nu+\left(1-R_{e}\right) \frac{m_{e}}{R_{e}} \frac{\nu}{z_{4}} .
\end{gathered}
$$

\section{Levels}

$$
\begin{gathered}
Y=H_{e}^{\nu}\left[N_{b}{ }^{\sigma} N_{s}{ }^{1-\sigma}\right]^{1-\nu}, \\
L_{b}=\frac{m_{b}}{R_{b}} z_{2} z_{3} \sigma(1-\nu) Y, \\
L_{e}=\frac{m_{e}}{R_{e}} \frac{\nu}{z_{4}} Y, \\
W_{s}=z_{7} \frac{Y}{N_{s}}, \\
W_{b}=\sigma(1-\nu) \frac{Y}{N_{b}}, \\
D=\left(1-w_{b} \kappa\right) L_{b}+\left(1-w_{e} \kappa\right) L_{e}, \\
\lambda_{f}=\frac{1-\beta_{f} R_{d}}{C_{f}}, \\
H_{s}+H_{b}+H_{e}=1 .
\end{gathered}
$$




\section{Efficiency policy frontier}

In this section, we present the outcome of the credit-output volatility trade-off for technology and housing demand shocks. The left panel in Fig. 9 shows the results with productivity shock while the right panel shows the results with a housing demand shock. The black square mark shows the outcome of creditoutput volatility under the baseline regime (constant LTV ratios). This is compared with the outcome under the generic CcLTV regime (red dash-dot line) and the sector-specific regime (blue dashed line).
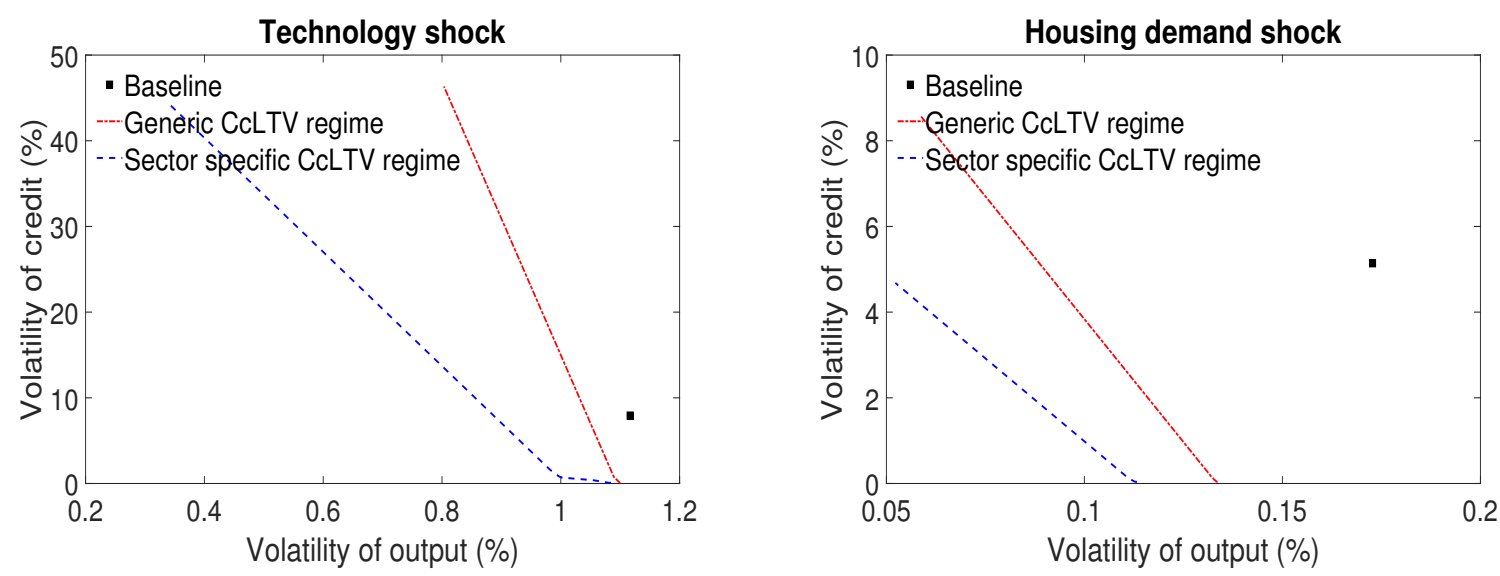

Figure 9: Credit-output stability trade-off. Left panel: productivity shock; right panel: housing demand shock.

Consistent with the findings in the previous sections, the results show that the sector-specific regime is more effective than the generic regime in enhancing financial and macroeconomic stability. The volatility frontiers for the two shocks present a clear trade-off between financial and macroeconomic stability. It is evident that both regimes are effective in enhancing financial stability but has limited impact in enhancing macroeconomic stability. The maximum attainable financial stability benefits can be achieved without compromising macroeconomic stability, irrespective of the shock hitting the economy. On the contrary, the maximum attainable macroeconomic stability benefits can only be achieved by compromising financial stability. With the exception of the sector-specific regime when the economy is hit by a housing demand shock, a maximum attainable reduction in output volatility is only feasibly at a cost of higher credit volatility. 